Article

\title{
Method of Moments Applied to Most-Likely High-Temperature Free-Radical Polymerization Reactions
}

\author{
Hossein Riazi ${ }^{1}$, Ahmad Arabi Shamsabadi ${ }^{1}$, Michael C. Grady ${ }^{2}$, Andrew M. Rappe ${ }^{3}$ and \\ Masoud Soroush ${ }^{1, *}$ \\ 1 Department of Chemical \& Biomedical Engineering, Drexel University, Philadelphia, PA 19104, USA; \\ hr339@drexel.edu (H.R.); neginali@sas.upenn.edu (A.A.S.) \\ 2 Axalta Coating Systems, Philadelphia Navy Yard, PA 19112, USA; mike.grady@axalta.com \\ 3 Department of Chemistry, University of Pennsylvania, Philadelphia, PA 19104-6323, USA; \\ rappe@sas.upenn.edu \\ * Correspondence: soroushm@drexel.edu; Tel.: +1-215-895-1710
}

Received: 13 July 2019; Accepted: 19 September 2019; Published: 26 September 2019

\begin{abstract}
Many widely-used polymers are made via free-radical polymerization. Mathematical models of polymerization reactors have many applications such as reactor design, operation, and intensification. The method of moments has been utilized extensively for many decades to derive rate equations needed to predict polymer bulk properties. In this article, for a comprehensive list consisting of more than 40 different reactions that are most likely to occur in high-temperature free-radical homopolymerization, moment rate equations are derived methodically. Three types of radicals-secondary radicals, tertiary radicals formed through backbiting reactions, and tertiary radicals produced by intermolecular chain transfer to polymer reactions-are accounted for. The former tertiary radicals generate short-chain branches, while the latter ones produce long-chain branches. In addition, two types of dead polymer chains, saturated and unsaturated, are considered. Using a step-by-step approach based on the method of moments, this article guides the reader to determine the contributions of each reaction to the production or consumption of each species as well as to the zeroth, first and second moments of chain-length distributions of live and dead polymer chains, in order to derive the overall rate equation for each species, and to derive the rate equations for the leading moments of different chain-length distributions. The closure problems that arise are addressed by assuming chain-length distribution models. As a case study, $\beta$-scission and backbiting rate coefficients of methyl acrylate are estimated using the model, and the model is then applied to batch spontaneous thermal polymerization to predict polymer average molecular weights and monomer conversion. These predictions are compared with experimental measurements.
\end{abstract}

Keywords: method of moments; free-radical polymerization; methyl acrylate; thermal polymerization; high-temperature polymerization

\section{Introduction}

Free-radical polymerization has been used widely to produce a variety of synthetic polymers. The polymerization involves three main (primary) reactions: initiation, propagation and termination [1]. In the initiation reaction, an initiator such as a thermal initiator usually generates free radicals at temperatures above $60^{\circ} \mathrm{C}[2,3]$. The polymerization may also start spontaneously (without adding any known initiator) by a monomer or impurities at high temperatures, typically $140-350{ }^{\circ} \mathrm{C}[4,5]$. In the propagation reactions, free radicals grow in size by reacting with monomers. In the termination reactions, growing macroradicals react with each other to form dead polymer chains. Vinyl, vinylidene, 
acrylates, and methacrylates are four well-known families of monomers that can participate in free-radical polymerization.

In addition to the primary reactions, free-radical polymerization may involve other reactions, which are known as the secondary reactions. The extent of contribution of each secondary reaction to free-radical polymerization depends on the monomer type, polymerization temperature, and polymerization medium type [6].

Styrene and alkyl acrylates are known to undergo monomer self-initiation, which is a secondary reaction [4,7-9]. Monomer self-initiation is a prevalent secondary reaction in the high-temperature polymerization of many monomers. In case of acrylate monomers, the reaction is significant over $140{ }^{\circ} \mathrm{C}$ and potentially obviates the need for a thermal initiator, such as benzoyl peroxide, ammonium persulfate, or azobisisobutyronitrile, to initiate the polymerization [3]. Backbiting and $\beta$-scission are two other prevalent secondary reactions in the high-temperature free-radical polymerization of acrylates, while their rates are low around $60-90^{\circ} \mathrm{C}$. Backbiting (intramolecular chain-transfer-to-polymer) reactions produce tertiary radials, which can subsequently propagate and generate short chain branches. The tertiary radical can also participate in a $\beta$-scission reaction, which generates a secondary radical and a macromonomer. These tertiary radicals can also undergo a migration reaction along the chain backbone [10]. Intermolecular chain-transfer-to-polymer reactions also produce tertiary radicals, which can subsequently propagate and generate long chain branches. In case of free-radical polymerization in the presence of a solvent, chain transfer to solvent can also occur. Transfer to chain transfer agents is another secondary reaction, which occurs when a transfer agent is present in the reaction medium. Many of these secondary reactions are interdependent. For example, the extent of the $\beta$-scission reaction is dependent on the concentration of tertiary radicals formed by backbiting and chain-transfer-to-polymer reactions. Thus, comprehensive models that account for all likely reactions that occur are needed to predict polymer properties reliably.

Given a set of postulated polymerization reactions, one can describe the reaction medium dynamics using one of the four widely-used methods: the method of moments, the tendency modeling, the Monte Carlo simulation, and the Predici simulation package [11]. The tendency modeling can be viewed as a very simplified form of the method of moments [12]; it provides less information than the method of moments. Kinetic Monte Carlo simulations have also been used for modeling polymerization systems. However, it is computationally expensive [13]. Predici is a commercial simulation package used for modeling of polymerization systems [14]. It is able to calculate entire chain-length distributions. Usually, but not always, these methods provide predictions that are in agreement [15].

The method of moments is a powerful and cost-effective method of simulating radical polymerization in different polymerization media [16-19]. It has been used to simulate emulsion copolymerization of vinylidene fluoride and hexafluoropropylene, estimate unavailable kinetic parameters, and predict molecular weight and chain end distributions [18]. Kalfas and Ray used this method to estimate monomer conversion inside particles in a suspension polymerization of vinyl acetate [19]. In the case of running a polymerization in a heterogeneous medium, for which the partitioning coefficient of a monomer between oil and water phases is unknown, the method of moments can be used to estimate the unknown parameter [20]. By dividing an entire range of molecular weights into a limited number of intervals, the method of moments is capable of predicting molecular-weight distributions that can be compared with what is measured experimentally by gel-permeation chromatography [21]. The method of moments was also used to study reaction kinetics in photochemically-mediated atom transfer radical polymerization (ATRP) [22]. In addition, the method of moments enables understanding of the concentrations of free ligands, catalysts, and initiators. Nitroxide-mediated polymerization (NMP) and reversible addition-fragmentation transfer (RAFT) polymerization were also studied by the method of moments approach [23]. In the latter case, one can assess the effect of RAFT agent concentration and rate constants of involved reactions on final polymer properties [24]. 
Several tutorial and review papers on the method of moments have been published. Mastan and Zhu [25] published a tutorial paper on the method of moments. They considered free-radical polymerization reactions such as initiation, propagation, and termination, but did not account for secondary reactions like monomer self-initiation, backbiting or $\beta$-scission [25]. Zhou and Luo [26], in their tutorial paper, focused on method of moments modeling of only living radical polymerization methods such as ATRP, RAFT, and NMP [26]. Bachmann et al. [27] applied the method of moments to a set of polymerization reactions including branching, scission and crosslinking, and concentrated on addressing the closure problems that arise when scission reactions are accounted for. The dependence of the rate of production of a moment of a distribution on a higher-order moment of the same distribution has been referred to as a closure problem. Their formulation allowed for relaxing the assumption of one radical per live chain. However, they did not fully consider backbiting or short-length branching [27]. Other articles on this topic either have not differentiated the radical types (secondary vs. tertiary) or have not fully treated challenging reactions such as $\beta$-scission [28-30].

The survey of the literature points to a need for: (i) the derivation of method of moments equations for a comprehensive set of most likely reactions in high-temperature free-radical polymerization; and (ii) a systematic method for the derivation of the contributions of new reactions to moment rate equations when a new reaction must be accounted for. This article was prepared to address these two needs. Based on a comprehensive list of the most likely reactions in high-temperature free-radical homo-polymerization of acrylates, Table S1 (Supporting Information) [31-38], the reader learns how to systematically calculate the contributions of each reaction to different moments and to the production or consumption of different species. Such a comprehensive list consisting of 44 most likely reactions in free-radical polymerization has not been considered elsewhere. $\beta$-scission reactions are fully studied herein, and the scissions from both the right-hand side (RHS) and the left-hand side (LHS) of a tertiary radical are considered. Closed-form rate equations are derived for each scission side to describe the contributions of the reaction to the rates of chain-length distribution moments and production/consumption of different chemical species. Three types of radicals and two types of dead polymer chains are considered. The approach presented herein enables the reader to derive easily and systematically new rate equations when a new reaction must be accounted for. As a case study, self-initiated bulk homopolymerization of methyl acrylate (MA) in a batch reactor is considered. Method of moments predictions of conversion and polymer average molecular weights are compared with measurements from polymer sample analyses.

\section{Rate Equations}

When using the method of moments, it is essential to correctly calculate the contributions of each reaction to the moments of the chain-length distributions of species that are of interest. For example, the $j$ th moment of the chain-length distribution (CLD) of secondary live polymer chains is:

$$
\rho_{j}^{* *}=\sum_{n=0}^{\infty} n^{j}\left[R_{n}^{* *}\right], \quad j=0,1,2, \cdots
$$

where $n$ is the length (number of monomer units) of a polymer chain, $\left[R_{n}^{* *}\right]$ is the molar concentration of live chains that have a secondary radical and $n$ monomer units, and $\rho_{j}^{* *}$ is the $j$ th moment of the chain-length distribution of the secondary radicals. For each class of polymer chains, from the zeroth, first and second moments of the CLD of the chains, one can calculate the number-average and weight-average chain lengths as well as the dispersity of the CLD. The zeroth moment of the CLD of a polymer class is the molar concentration of the polymer class, and the first moment times the monomer molecular weight is the mass concentration of the polymer class [39,40]. Similarly, moments of other CLDs can be defined:

$$
\rho_{j}^{* * *}=\sum_{n=0}^{\infty} n^{j}\left[R_{n}^{* * *}\right], \quad j=0,1,2, \cdots
$$




$$
\begin{gathered}
\widetilde{\rho}_{j}^{* * *}=\sum_{n=0}^{\infty} n^{j}\left[\widetilde{R}_{n}^{* * *}\right], j=0,1,2, \cdots \\
\delta_{j}=\sum_{n=0}^{\infty} n^{j}\left[D_{n}\right], \quad j=0,1,2, \cdots \\
\epsilon_{j}=\sum_{n=0}^{\infty} n^{j}\left[U_{n}\right], \quad j=0,1,2, \cdots
\end{gathered}
$$

where $\left[R_{n}^{* * *}\right]$ is the molar concentration of $n$-monomer-unit live chains that have a tertiary radical produced by intermolecular chain transfer to polymer reactions, $\left[\widetilde{R}_{n}^{* * *}\right]$ is the molar concentration of $n$-monomer-unit live chains that have a tertiary radical produced by backbiting reactions, $\left[D_{n}\right]$ is the molar concentration of $n$-monomer-unit dead chains without a terminal double bond, and $\left[U_{n}\right]$ is the molar concentration of $n$-monomer-unit dead chains with a terminal double bond. $\rho_{j}^{* * *}, \widetilde{\rho}_{j}^{* * *}, \epsilon_{j}$, and $\delta_{j}$ are the $j$ th moments of the chain-length distributions of the $R_{n}^{* * *}, \widetilde{R}_{n}^{* * *}, U_{n}$ and $D_{n}$ polymer chains, respectively.

\subsection{Initiation with Conventional Thermal Initiators}

In this reaction, a molecule of a thermal initiator such as ammonium persulfate or potassium persulfate decomposes into two free radicals:

$$
I \stackrel{k_{d}}{\rightarrow} 2 R_{0}^{*}
$$

where $I$ and $R_{0}^{*}$, respectively, represent an initiator molecule and a monoradical. Contributions of this reaction to the consumption of the initiator and the generation of free radicals with a length of zero (with no monomer units) are given by:

$$
\begin{gathered}
r_{I}=-k_{d}[I] \\
r_{R_{0}^{*}}=2 f k_{d}[I]
\end{gathered}
$$

where $f$ is the free-radical generation efficiency of the initiator. An initiator efficiency of less than $100 \%$ has been attributed to a phenomenon called the cage effect [41]. It is worth noting that this reaction does not have any monomer-unit contributions to the zeroth, first or second moments of live chains as the length (number of monomer units) of the produced live radicals is zero.

\subsection{Self-Initiation of Monomers}

Previous studies by our group [42-44] showed that three alkyl acrylate monomers react and form one monoradical with the length of one monomer unit, $R_{1}^{* *}$, and one monoradical with the length of two monomer units, $R_{2}^{* *}$ :

$$
3 M \stackrel{k_{i}}{\rightarrow} R_{1}^{* *}+R_{2}^{* *}
$$

Contributions of this reaction to the production/consumption rates of monomer $(M)$, secondary radicals with one monomer unit length $\left(R_{1}^{* *}\right)$, secondary radicals with two monomer units length $\left(R_{2}^{* *}\right)$, zeroth moment of secondary radicals $\left(\rho_{0}^{* *}\right)$, first moment of secondary radicals $\left(\rho_{1}^{* *}\right)$, and second moment of the secondary radicals $\left(\rho_{2}^{* *}\right)$ are given by:

$$
\begin{gathered}
r_{\mathrm{M}}=-3 k_{i}[M]^{2} \\
r_{R_{1}^{* *}}=k_{i}[M]^{2} \\
r_{R_{2}^{* *}}=k_{i}[M]^{2}
\end{gathered}
$$




$$
\begin{aligned}
& r_{\rho_{0}^{* *}}=\left(1^{0}+2^{0}\right) k_{i}[M]^{2} \\
& r_{\rho_{1}^{* *}}=\left(1^{1}+2^{1}\right) k_{i}[M]^{2} \\
& r_{\rho_{2}^{* *}}=\left(1^{2}+2^{2}\right) k_{i}[M]^{2}
\end{aligned}
$$

In the last three (moment) rate equations, the " 1 " accounts for the single monomer unit of the secondary radical $R_{1}^{* *}$ and " 2 " for the two monomer units of the secondary radical $R_{2}^{* *}$. In the case of methacrylates, the monomers undergo the overall (apparent) reactions [42-44]:

$$
\begin{gathered}
3 M \stackrel{k_{i}}{\rightarrow} R_{1}^{* *}+R_{2}^{* *} \\
2 M \stackrel{k_{d i m}}{\rightarrow} D_{2}
\end{gathered}
$$

Contributions of these reactions to the production rates of monomer $(M)$, secondary radicals with one monomer unit length $\left(R_{1}^{* *}\right)$, secondary radicals with two monomer unit length $\left(R_{2}^{* *}\right)$, dead polymer chain with two monomer unit length $\left(D_{2}\right)$, zeroth moment of secondary radicals $\left(\rho_{0}^{* *}\right)$, first moment of secondary radicals $\left(\rho_{1}^{* *}\right)$, and second moment of the secondary radicals $\left(\rho_{2}^{* *}\right)$ are given by:

$$
\begin{gathered}
r_{\mathrm{M}}=-\left(3 k_{i}+2 k_{\text {dim }}\right)[M]^{2} \\
r_{R_{1}^{* *}}=k_{i}[M]^{2} \\
r_{R_{2}^{* *}}=k_{i}[M]^{2} \\
r_{\rho_{0}^{* *}}=\left(1^{0}+2^{0}\right) k_{i}[M]^{2} \\
r_{\rho_{1}^{* *}}=\left(1^{1}+2^{1}\right) k_{i}[M]^{2} \\
r_{\rho_{2}^{* *}}=\left(1^{2}+2^{2}\right) k_{i}[M]^{2} \\
r_{\delta_{0}}=\left(2^{0}\right) k_{\text {dim }}[M]^{2} \\
r_{\delta_{1}}=\left(2^{1}\right) k_{\text {dim }}[M]^{2} \\
r_{\delta_{2}}=\left(2^{2}\right) k_{\text {dim }}[M]^{2}
\end{gathered}
$$

\subsection{Propagation Reactions}

In these reactions, a live chain reacts with a monomer molecule and forms a new live chain that is one monomer unit longer than the reactant live chain. For example, a secondary radical reacts with a monomer molecule and forms a new secondary radical that is one monomer unit longer than the reactant secondary:

$$
R_{n}^{* *}+M \stackrel{k_{p}}{\rightarrow} R_{n+1}^{* *}
$$

Since there is no change in the population of secondary radicals upon the occurrence of this reaction, the contribution of this reaction to the zeroth moment of the chain-length distribution of the secondary radicals is zero:

$$
r_{\rho_{0}^{* *}}=k_{p}[M] \sum(n+1)^{0}\left[R_{n}^{* *}\right]-k_{p}[M] \sum n^{0}\left[R_{n}^{* *}\right]=0
$$

The contributions of this reaction to the production of other species and to other moments are given by:

$$
\begin{aligned}
& r_{M}=-k_{p}[M] \sum\left[R_{n}^{* *}\right]=-k_{p}[M] \rho_{0}^{* *} \\
& r_{\rho_{1}^{* *}}=k_{p}[M]\left(\sum(n+1)\left[R_{n}^{* *}\right]-\sum n\left[R_{n}^{* *}\right]\right)=k_{p}[M] \sum\left[R_{n}^{* *}\right]=k_{p}[M] \rho_{0}^{* *}
\end{aligned}
$$




$$
\begin{gathered}
r_{\rho_{2}^{* *}}=k_{p}[M]\left(\sum(n+1)^{2}\left[R_{n}^{* *}\right]-\sum n^{2}\left[R_{n}^{* *}\right]\right)=k_{p}[M] \sum(2 n+1)\left[R_{n}^{* *}\right] \\
=k_{p}[M]\left(2 \rho_{1}^{* *}+\rho_{0}^{* *}\right) \\
r_{R_{0}^{*}}=-k_{p}[M]\left[R_{0}^{*}\right] \\
r_{R_{1}^{* *}}=k_{p}[M]\left(\left[R_{0}^{*}\right]-\left[R_{1}^{* *}\right]\right) \\
r_{R_{2}^{* *}}=k_{p}[M]\left(\left[R_{1}^{*}\right]-\left[R_{2}^{* *}\right]\right)
\end{gathered}
$$

Note that the rate equations satisfy $r_{M}+r_{\rho_{1}^{* *}}=0$, confirming that the reaction does not change the total number of monomer units in the system. Tertiary radicals of types $R_{n}^{* * *}$ and $\widetilde{R}_{n}^{* * *}$ also participate in propagation reactions. As they are more stable than secondary radicals, their propagation reaction rate coefficients are smaller than those of secondary radicals. As a rule of thumb, the propagation rate coefficient of tertiary radicals $\left(k_{p}^{t}\right)$ is 1000 times less than that of the secondary radicals $\left(k_{p}\right)$ [45]. The product of propagation of a tertiary radical is a secondary radical with one monomer unit longer than the tertiary radical.

$$
\begin{aligned}
& R_{n}^{* * *}+M \stackrel{k_{p}^{t}}{\rightarrow} R_{n+1}^{* *} \\
& \widetilde{R}_{n}^{* * *}+M \stackrel{k_{p}^{t}}{\rightarrow} R_{n+1}^{* *}
\end{aligned}
$$

The occurrence of the reaction (35) leads to the formation of long chain branching, while the reaction (36) causes the formation of short chain branches. The contributions of these two reactions to the production rates of different species as well as rates of the moments are presented in the SI (Equations (S1)-(S8) and (S9)-(S16))

\subsection{De-Propagation}

De-propagation is a reaction that is significant in high-temperature polymerization of methacrylates. In this reaction, a secondary radical generates a monomer molecule and a new secondary radical which is one monomer unit shorter than the reactant secondary radical:

$$
R_{n+1}^{* *} \stackrel{k_{-p}}{\rightarrow} R_{n}^{* *}+M
$$

The contribution of this reaction to the production and consumption of different species as well as to the moments are as follows:

$$
\begin{gathered}
r_{M}=k_{-p} \rho_{0}^{* *} \\
r_{\rho_{0}^{* *}}=0 \\
r_{\rho_{1}^{* *}}=-k_{-p} \rho_{0}^{* *} \\
r_{\rho_{2}^{* *}}=-k_{-p}\left(2 \rho_{1}^{* *}-\rho_{0}^{* *}\right)
\end{gathered}
$$

\subsection{Backbiting}

A backbiting reaction converts a secondary radical to a tertiary counterpart. This reaction is prevalent at high temperatures and involves the abstraction of a hydrogen by a secondary radical from its backbone:

$$
R_{n}^{* *} \stackrel{k_{b b}}{\rightarrow} \widetilde{R}_{n}^{* * *}
$$

To abstract a hydrogen, the chain head with a secondary radical (on carbon atom \#1) bends and abstracts a hydrogen usually from carbon \#5, or less-likely carbon \#7; the radical moves from carbon \#1 to carbon \#5 or \#7. Quantum chemical calculations have shown that carbon \#5 is the most probable place for hydrogen abstraction (See Figure 1) [46]. The reaction of a monomer with the produced tertiary radical causes the formation of a short branch in the polymer chain. One challenge here is that 
this tertiary radical can migrate along the backbone, which is discussed in the next section. Backbiting affects just the rates of moments of secondary and tertiary radicals as follows:

$$
\begin{aligned}
& r_{\rho_{0}^{* *}}=-r_{\widetilde{\rho}_{0}^{* * *}}=-k_{b b} \sum n^{0}\left[R_{n}^{* *}\right]=-k_{b b} \rho_{0}^{* *} \\
& r_{\rho_{1}^{* *}}=-r_{\widetilde{\rho}_{1}^{* * *}}=-k_{b b} \sum n^{1}\left[R_{n}^{* *}\right]=-k_{b b} \rho_{1}^{* *} \\
& r_{\rho_{2}^{* *}}=-r_{\widetilde{\rho}_{2}^{* * *}}=-k_{b b} \sum n^{2}\left[R_{n}^{* *}\right]=-k_{b b} \rho_{2}^{* *}
\end{aligned}
$$

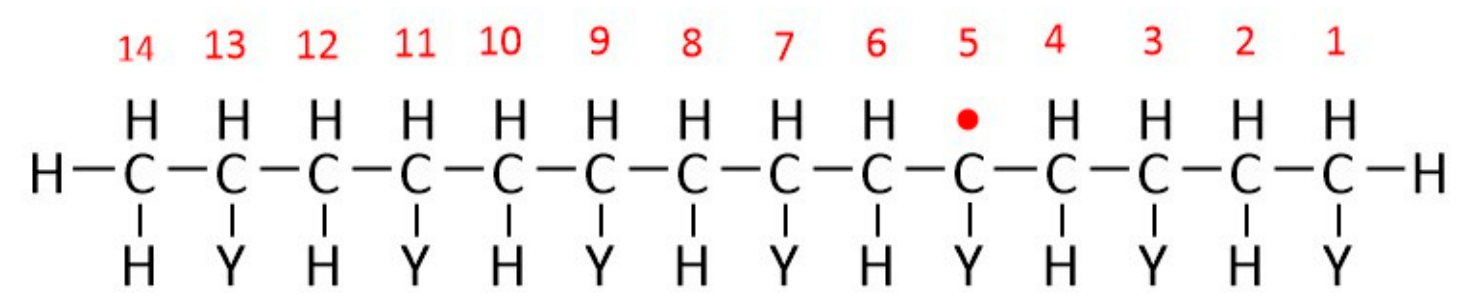

Figure 1. A polymer chain with seven monomer units with a tertiary radical on carbon \#5. Y represents a functional group like an alkyl group.

\subsection{Mid-Chain Radical Migration}

A tertiary radical can migrate along the backbone of the live polymer chain. In the case of a tertiary radical of the type $\widetilde{R}_{n}^{* * *}$ :

$$
\widetilde{R}_{n}^{* * *} \stackrel{k_{m i g}}{\rightarrow} R_{n}^{* * *}
$$

This reaction has been reported to occur at high-temperature, low-monomer-concentration polymerization of acrylates [10,47]. Mid-chain radicals that are formed by backbiting usually undergo this migration reaction. Mid-chain radicals formed by macromonomer propagation can also participate in this reaction. Although this reaction does not alter the tertiary nature of radicals, it may change branch sizes (if propagation occurs after migration) or the macromonomer length (if scission happens after migration) [48]. The migration reaction has been reported to be 50 times slower than backbiting but 15 times faster than $\beta$-Scission [48]. The occurrence of this reaction causes the generation of low mass macromonomers in polymerizing systems [49]. Migration of mid-chain radicals usually happens between every other monomer $(n: n+4)$; this is why $\beta$-scission reaction, which usually occurs after several migration steps, produces macromonomers with different distribution chain length.

Contributions of the reaction (46) to the rates of moments are:

$$
\begin{aligned}
& r_{\widetilde{\rho}_{0}^{* * *}}=-r_{\rho_{0}^{* * *}}=-k_{m i g} \widetilde{\rho}_{0}^{* * *} \\
& r_{\widetilde{\rho}_{1}^{* * *}}=-r_{\rho_{1}^{* * *}}=-k_{m i g} \widetilde{\rho}_{1}^{* * *} \\
& r_{\widetilde{\rho}_{2}^{* * *}}=-r_{\rho_{2}^{* * *}}=-k_{m i g} \widetilde{\rho}_{2}^{* * *}
\end{aligned}
$$

\section{7. $\beta$-Scission Reaction of $\widetilde{R}_{n}^{* * *}$}

This $\beta$-scission reaction converts a tertiary radical of type $\widetilde{R}_{n}^{* * *}$ to a secondary radical $R_{m}^{* *}$ and a macromonomer (unsaturated dead polymer chain) $U_{n-m}$ that possesses a shorter length than its parent chain. The reaction is prevalent at high temperatures and involves a carbon-carbon bond scission, which lowers polymer molecular weight [50]. $\beta$-Scission can happen from both RHS and LHS of a tertiary radical where the scission side determines the length of the produced macromonomer as well as the length of the secondary radical. Equations (50) and (51), respectively, show scission from the RHS and LHS of a chain with a free electron on the tertiary carbon \#5. In Figure 1, if scission happens 
from the LHS of the tertiary radical, the covalent bond between carbons \#6 and \#7 breaks, while the scission from the RHS causes the breakage of the bond between carbons \#3 and \#4. Regardless of the chain length, scission from the RHS of the tertiary carbon \#5 always produces a secondary radical with two-monomer-unit length, while the scission from the LHS of the same tertiary carbon always produces a macromonomer with three-monomer-unit length:

$$
\begin{aligned}
& \widetilde{R}_{n}^{* * *} \stackrel{k_{\beta}}{\rightarrow} R_{2}^{* *}+U_{n-2} \\
& \widetilde{R}_{n}^{* * *} \stackrel{k_{\beta}}{\rightarrow} R_{n-3}^{* *}+U_{3}
\end{aligned}
$$

It has been reported that a secondary radical is most likely to abstract a hydrogen from carbon \#5 [51]. Thus, in a subsequent $\beta$-Scission reaction, mostly like the $C_{3}-C_{4}$ or $C_{6}-C_{7}$ carbon-carbon bond breaks. Here, we develop equations describing the contribution of this scission site to moment equations. However, the same method is applicable if one needs to account for scission from other tertiary carbons. We start by deriving the contributions of a single chain with seven monomer units (Figure 1) and then generalize them for a chain with $n$ monomer units. Different sets of equations for the RHS and LHS reactions are derived, as the reaction products are different in the two cases.

$$
r_{\rho_{0, R}^{* *}}=\frac{1}{2} k_{\beta}\left[\widetilde{R}_{7}^{* * *}\right] \times 2^{0}=\frac{1}{2} k_{\beta}\left[\widetilde{R}_{7}^{* * *}\right]
$$

where the symbol $R$ in $\rho_{0, R}^{* *}$ represents that the scission occurs from the RHS. The pre-factor $\frac{1}{2}$ also emphasizes that the scission is equally likely from the RHS and LHS. Generalizing this, the contribution of an $n$-monomer-unit chain to the zero moment of secondary radicals is:

$$
r_{\rho_{0, R}^{* *}}=\frac{1}{2} k_{\beta}\left[\widetilde{R}_{n}^{* * *}\right] \times 2^{0}=\frac{1}{2} k_{\beta}\left[\widetilde{R}_{n}^{* * *}\right]
$$

and the contribution of all chains with different lengths is given by:

$$
r_{\rho_{0, R}^{* *}}=\sum \frac{1}{2} k_{\beta}\left[\widetilde{R}_{n}^{* * *}\right]=\frac{1}{2} k_{\beta} \widetilde{\rho}_{0}^{* * *}
$$

Similarly, the contributions to the first and second moments of the produced secondary radicals are given by:

$$
\begin{gathered}
r_{\rho_{1, R}^{* *}}=\sum \frac{1}{2} k_{\beta}\left[\widetilde{R}_{n}^{* * *}\right] \times 2=k_{\beta} \widetilde{\rho}_{0}^{* * *} \\
r_{\rho_{2, R}^{* *}}=\sum \frac{1}{2} k_{\beta}\left[\widetilde{R}_{n}^{* * *}\right] \times 2^{2}=2 k_{\beta} \widetilde{\rho}_{0}^{* * *}
\end{gathered}
$$

For the scission from LHS of tertiary carbon \#5, Equation (51), the following relations are developed to account the contribution of the reaction to zero, first and second moments of produced secondary radicals:

$$
\begin{gathered}
r_{\rho_{0, L}^{* *}}=\sum \frac{1}{2} k_{\beta}\left[\widetilde{R}_{n}^{* * *}\right]=\frac{1}{2} k_{\beta} \widetilde{\rho}_{0}^{* * *} \\
r_{\rho_{1, L}^{* *}}=\sum \frac{1}{2} k_{\beta}\left[\widetilde{R}_{n}^{* * *}\right] \times(n-3)=\frac{1}{2} k_{\beta}\left(\widetilde{\rho}_{1}^{* * *}-3 \widetilde{\rho}_{0}^{* * *}\right) \\
r_{\rho_{2, L}^{* *}}=\sum \frac{1}{2} k_{\beta}\left[\widetilde{R}_{n}^{* * *}\right] \times(n-3)^{2}=\frac{1}{2} k_{\beta}\left(\widetilde{\rho}_{2}^{* * *}-6 \widetilde{\rho}_{1}^{* * *}+9 \widetilde{\rho}_{0}^{* * *}\right)
\end{gathered}
$$

Following the same concept, contributions of this reaction to the rates of moments of tertiary radicals as well as macromonomers come below:

$$
r_{\widetilde{\rho}_{0, L}^{* * *}}=r_{\widetilde{\rho}_{0, R}^{* * *}}=-\sum \frac{1}{2} k_{\beta}\left[\widetilde{R}_{n}^{* * *}\right]=-\frac{1}{2} k_{\beta} \widetilde{\rho}_{0}^{* * * *}
$$




$$
\begin{gathered}
r_{\widetilde{\rho}_{1, L}^{* * *}}=r_{\widetilde{\rho}_{1, R}^{* * *}}=-\sum \frac{1}{2} k_{\beta} \times n\left[\widetilde{R}_{n}^{* * *}\right]=-\frac{1}{2} k_{\beta} \widetilde{\rho}_{1}^{* * *} \\
r_{\widetilde{\rho}_{2, L}^{* * *}}=r_{\widetilde{\rho}_{2, R}^{* * *}}=-\sum \frac{1}{2} k_{\beta} \times n^{2}\left[\widetilde{R}_{n}^{* * *}\right]=-\frac{1}{2} k_{\beta} \widetilde{\rho}_{2}^{* * *} \\
r_{\epsilon_{0, R}}=\sum \frac{1}{2} k_{\beta}\left[\widetilde{R}_{n}^{* * *}\right]=\frac{1}{2} k_{\beta} \widetilde{\rho}_{0}^{* * *} \\
r_{\epsilon_{1, R}}=\sum \frac{1}{2} k_{\beta} \times(n-2)\left[\widetilde{R}_{n}^{* * *}\right]=\frac{1}{2} k_{\beta}\left(\widetilde{\rho}_{1}^{* * *}-2 \widetilde{\rho}_{0}^{* * *}\right. \\
r_{\epsilon_{2, R}}=\sum \frac{1}{2} k_{\beta} \times(n-2)^{2}\left[\widetilde{R}_{n}^{* * *}\right]=\frac{1}{2} k_{\beta}\left(\widetilde{\rho}_{2}^{* * *}-4 \widetilde{\rho}_{1}^{* * *}+4 \widetilde{\rho}_{0}^{* * *}\right) \\
r_{\epsilon_{0, L}}=\sum \frac{1}{2} k_{\beta}\left[\widetilde{R}_{n}^{* * * *}\right]=\frac{1}{2} k_{\beta} \widetilde{\rho}_{0}^{* * *} \\
r_{\epsilon_{1, L}}=\sum \frac{1}{2} k_{\beta} \times 3\left[\widetilde{R}_{n}^{* * *}\right]=\frac{3}{2} k_{\beta} \widetilde{\rho}_{0}^{* * *} \\
r_{\epsilon_{2, L}}=\sum \frac{1}{2} k_{\beta} \times 9\left[\widetilde{R}_{n}^{* * *}\right]=\frac{9}{2} k_{\beta} \widetilde{\rho}_{0}^{* * *}
\end{gathered}
$$

\section{8. $\beta$-Scission Reaction of $R_{n}^{* * *}$}

Tertiary radicals formed through chain transfer to polymer $\left(R_{n}^{* * *}\right)$ also undergo scission from RHS and LHS. The most important difference between the $\beta$-scission reaction of $R_{n}^{* * *}$ and $\widetilde{R}_{n}^{* * *}$ is the number of possible sites for scission. As mentioned in Section $2.7, \widetilde{R}_{n}^{* * *}$ most likely undergoes scission from carbon \#5 or less likely from carbon \#7. It means that just one or two sites are available for scission. On the other hand, $R_{n}^{* * *}$ can undergo scission from all available tertiary carbons along its backbone. As in Section 2.7, the $\beta$-Scission reaction of a tertiary radical of type $R_{n}^{* * *}$ generates a secondary radical and a macromonomer:

$$
\begin{aligned}
& R_{n}^{* * *} \stackrel{k_{\beta}}{\rightarrow} R_{m}^{* *}+U_{n-m} \\
& R_{n}^{* * *} \stackrel{k_{\beta}}{\rightarrow} R_{n-m}^{* *}+U_{m}
\end{aligned}
$$

\begin{tabular}{|c|c|c|}
\hline Free electron on tertiary carbon \# 13 & $\mathrm{R}_{7} \stackrel{* * \star}{\longrightarrow} \mathrm{R}_{6}^{* *}+\mathrm{U}_{1}$ & Not Possible \\
\hline Free electron on tertiary carbon \# 11 & $\mathrm{R}_{7}{ }^{* * *} \longrightarrow \mathrm{R}_{5}^{* *}+\mathrm{U}_{2}$ & $\mathrm{R}_{7}^{* * *} \longrightarrow \mathrm{R}_{1}^{* *}+\mathrm{U}_{6}$ \\
\hline Free electron on tertiary carbon \# 9 & $\mathrm{R}_{7}{ }^{* * *} \longrightarrow \mathrm{R}_{4}{ }^{* *}+\mathrm{U}_{3}$ & $\mathrm{R}_{7}{ }^{* *} \longrightarrow \mathrm{R}_{2}^{* *}+\mathrm{U}_{5}$ \\
\hline Free electron on tertiary carbon \# 7 & $\mathrm{R}_{7} \stackrel{\text { ***}}{\longrightarrow} \mathrm{R}_{3}^{* *}+\mathrm{U}_{4}$ & $\mathrm{R}_{7}{ }^{* *} \longrightarrow \mathrm{R}_{3}^{* *}+\mathrm{U}_{4}$ \\
\hline Free electron on tertiary carbon \# 5 & $\mathrm{R}_{7}{ }^{* \star \star} \longrightarrow \mathrm{R}_{2}^{* \star}+\mathrm{U}_{5}$ & $\mathrm{R}_{7}^{* \star *} \longrightarrow \mathrm{R}_{4}^{* *}+\mathrm{U}_{3}$ \\
\hline Free electron on tertiary carbon \# 3 & $\mathrm{R}_{7} \stackrel{* \star \star}{\longrightarrow} \mathrm{R}_{1}{ }^{* *}+\mathrm{U}_{6}$ & $\mathrm{R}_{7}{ }^{* * *} \longrightarrow \mathrm{R}_{5}{ }^{* *}+\mathrm{U}_{2}$ \\
\hline
\end{tabular}

Figure 2 shows the products of both LHS and RHS $\beta$-Scission reactions of a chain with seven monomer units. To write the contributions of this reaction to the consumption and generation of different species as well as rates of moments, we first consider scission from RHS and then scission from LHS where there is no chance for carbon $\# 13$ to participate in $\beta$-scission reaction.

\section{Right-side Scission}

Figure 2. Possible $\beta$-scission reactions for a chain with seven monomer units from right-hand side and left-hand side of a tertiary radical formed by transfer to polymer reaction. 
In the case of an RHS scission, only one reaction out of the six possible reactions can occur for a chain with seven monomer units every time, Figure 2. Thus, assuming that the reaction sites have the same reactivity to participate in the reaction and equal chances for RHS and LHS scissions for each tertiary radical, the probability of one site to participate in RHS scission is $\frac{1}{2} \times \frac{1}{6}$. The contributions of all possible six reactions of a seven-monomer-unit chain to the zeroth moment of the CLD of the tertiary radicals is:

$$
r_{\rho_{0, R}^{* * *}}=-\frac{1}{6} \times \frac{1}{2} k_{\beta}\left[R_{7}^{* * *}\right] \times 6
$$

Generalizing this, the contribution of an $n$-monomer-unit chain that has $(n-1)$ reaction sites is:

$$
r_{\rho_{0, R}^{* * *}}=-\frac{1}{n-1} \times \frac{1}{2} k_{\beta}\left[R_{n}^{* * *}\right] \times(n-1)
$$

and the contribution of all chains with different lengths is given by:

$$
r_{\rho_{0, R}^{* * *}}=-\sum \frac{1}{n-1} \times \frac{1}{2} k_{\beta}\left[R_{n}^{* * *}\right] \times(n-1)=-\frac{1}{2} k_{\beta} \rho_{0}^{* * * *}
$$

Similarly, the contributions to the first and second moments of the live chains with tertiary radicals are given by:

$$
\begin{aligned}
& r_{\rho_{1, R}^{* * *}}=-\sum \frac{1}{n-1} \times \frac{1}{2} n k_{\beta}\left[R_{n}^{* * *}\right] \times(n-1)=-\frac{1}{2} k_{\beta} \rho_{1}^{* * *} \\
& r_{\rho_{2, R}^{* * *}}=-\sum \frac{1}{n-1} \times \frac{1}{2} n^{2} k_{\beta}\left[R_{n}^{* * *}\right] \times(n-1)=-\frac{1}{2} k_{\beta} \rho_{2}^{* * *}
\end{aligned}
$$

The reaction (69) generates secondary radicals as well. As the list of reactions for RHS scission in Figure 2 shows, the contribution of the tertiary chain with seven monomer units to the zeroth moment of the CLD of the $R_{n}^{* *}$ radicals is:

$$
r_{\rho_{0, R}^{* *}}=+\frac{1}{6} \times \frac{1}{2} k_{\beta}\left[R_{7}^{* * *}\right] \times 6
$$

which for an $n$-monomer-unit tertiary chain that has $(n-1)$ reaction sites becomes:

$$
r_{\rho_{0, R}^{* *}}=+\frac{1}{n-1} \times \frac{1}{2} k_{\beta}\left[R_{n}^{* * *}\right] \times(n-1)
$$

and the contribution of all chains with different lengths is given by:

$$
r_{\rho_{0, R}^{* *}}=\sum \frac{1}{n-1} \times \frac{1}{2} k_{\beta}\left[R_{n}^{* * *}\right] \times(n-1)=\frac{1}{2} k_{\beta} \rho_{0}^{* * *}
$$

According to Figure 2, the scission reactions from RHS generate secondary live chains with 1, 2, 3, 4,5 , and 6 monomer units. Thus, the contributions of the tertiary chain with seven monomer units to the first moment of the CLD of the $R_{n}^{* *}$ radicals are:

$$
\begin{gathered}
r_{\rho_{1, R}^{* *}=} \frac{1}{6} \times \frac{1}{2} k_{\beta}\left[R_{7}^{* * *}\right] 6+\frac{1}{6} \times \frac{1}{2} k_{\beta}\left[R_{7}^{* * *}\right] 5+\frac{1}{6} \times \frac{1}{2} k_{\beta}\left[R_{7}^{* * *}\right] 4+\frac{1}{6} \\
\times \frac{1}{2} k_{\beta}\left[R_{7}^{* * *}\right] 3+\frac{1}{6} \times \frac{1}{2} k_{\beta}\left[R_{7}^{* * *}\right] 2+\frac{1}{6} \times \frac{1}{2} k_{\beta}\left[R_{7}^{* * *}\right] 1 \\
=\frac{1}{6} \times \frac{1}{2} k_{\beta}\left[R_{7}^{* * *}\right](1+2+3+4+5+6)
\end{gathered}
$$

which is the sum of the multiplication products of the rate of production of each secondary radical and the number of monomer units of the produced secondary radical. Generalizing this, the contribution of a tertiary chain with $n$ monomer units to the first moment of the CLD of the $R_{n}^{* *}$ radicals is:

$$
r_{\rho_{1, R}^{* *}}=\frac{1}{n-1} \times \frac{1}{2} k_{\beta}\left[R_{n}^{* * *}\right](1+2+3+4+\cdots+(n-1))
$$


Using the following identity [52]:

$$
1+2+3+4+\cdots+n=\frac{1}{2} n(n+1)
$$

one can write:

$$
1+2+3+\cdots+(n-1)=\frac{1}{2}(n-1) n
$$

Thus, the contribution of all chains with different lengths to the rate of the first moment of the CLD of the secondary radicals is given by:

$$
r_{\rho_{1, R}^{* *}}=\sum \frac{1}{n-1} \times \frac{1}{2} k_{\beta}\left[R_{n}^{* * *}\right]\left(\frac{1}{2}(n-1) n\right)=\frac{1}{4} k_{\beta} \sum\left[R_{n}^{* * *}\right](n)=\frac{1}{4} k_{\beta} \rho_{1}^{* * *}
$$

In a similar way, according to Figure 2, we can write the rate of change in the second moment of CLD of the secondary radicals upon RHS of a chain with seven monomer units:

$$
\begin{aligned}
r_{\rho_{2, R}^{* *}}= & \frac{1}{6} \times \frac{1}{2} k_{\beta}\left[R_{7}^{* * *}\right] 6^{2}+\frac{1}{6} \times \frac{1}{2} k_{\beta}\left[R_{7}^{* * *}\right] 5^{2}+\frac{1}{6} \times \frac{1}{2} k_{\beta}\left[R_{7}^{* * *}\right] 4^{2}+\frac{1}{6} \\
& \times \frac{1}{2} k_{\beta}\left[R_{7}^{* * *}\right] 3^{2}+\frac{1}{6} \times \frac{1}{2} k_{\beta}\left[R_{7}^{* * *}\right] 2^{2}+\frac{1}{6} \times \frac{1}{2} k_{\beta}\left[R_{7}^{* * *}\right] 1^{2} \\
& =\frac{1}{6} \times \frac{1}{2} k_{\beta}\left[R_{7}^{* * *}\right]\left(1^{2}+2^{2}+3^{2}+4^{2}+5^{2}+6^{2}\right)
\end{aligned}
$$

which is the sum of the products of the production rate of each secondary radical multiplied by the number of monomer units of the secondary radical that the reaction generates, raised to power two. The preceding equation for a chain with $n$ monomer units becomes:

$$
r_{\rho_{2, R}^{* *}}=\frac{1}{n-1} \times \frac{1}{2} k_{\beta}\left[R_{n}^{* * *}\right]\left(1^{2}+2^{2}+3^{2}+\cdots+(n-1)^{2}\right)
$$

Using the following identity [52]:

$$
1^{2}+2^{2}+3^{2}+\cdots+n^{2}=\frac{n(n+1)(2 n+1)}{6}
$$

one can write:

$$
1^{2}+2^{2}+3^{2}+\cdots+(n-1)^{2}=\frac{(n-1)(n)(2 n-1)}{6}
$$

Thus, the contribution of all chains with different lengths to the rate of the second moment of the CLD of the secondary radicals is given by:

$$
r_{\rho_{2, R}^{* *}}=\sum \frac{1}{n-1} \times \frac{1}{2} k_{\beta}\left[R_{n}^{* * *}\right] \frac{(n-1)(n)(2 n-1)}{6}=\frac{1}{12} k_{\beta}\left(2 \rho_{2}^{* * *}-\rho_{1}^{* * *}\right)
$$

The reaction (69) generates unsaturated dead polymers as well. Equations of (76) to (88) are exactly applicable for zeroth, first and second moments of the macromonomers:

$$
\begin{gathered}
r_{\epsilon_{0, R}}=\sum \frac{1}{n-1} \times \frac{1}{2} k_{\beta}\left[R_{n}^{* * *}\right] \times(n-1)=\frac{1}{2} k_{\beta} \rho_{0}^{* * *} \\
r_{\epsilon_{1, R}}=\sum \frac{1}{n-1} \times \frac{1}{2} k_{\beta}\left[R_{n}^{* * *}\right] \frac{1}{2}(n-1)(n)=\frac{1}{4} k_{\beta}\left(\rho_{1}^{* * *}\right) \\
r_{\epsilon_{2, R}}=\sum \frac{1}{n-1} \times \frac{1}{2} k_{\beta}\left[R_{n}^{* * *}\right] \frac{(n-1)(n)(2 n-1)}{6}=\frac{1}{12} k_{\beta}\left(2 \rho_{2}^{* * *}-\rho_{1}^{* * *}\right)
\end{gathered}
$$

The rate equations derived in this section satisfy $r_{\rho_{1}^{* * *}}+r_{\rho_{1}^{* *}}+r_{\epsilon_{1}}=0$, implying that the reaction does not change the total number of monomer units in the system. 
$\beta$-scission from the LHS of a tertiary radical of the type $R_{n}^{* * *}$ can also happen, which similarly produces a secondary radical and a macromonomer with less monomer units compared with the parental tertiary radical:

$$
R_{n}^{* * *} \stackrel{k_{\beta}}{\rightarrow} R_{n-m}^{* *}+U_{m}
$$

As Figure 2 shows, the LHS $\beta$-scission reaction produces species with different lengths from those of RHS $\beta$-Scission reaction. Thus, a different set of equations is needed to describe the dynamic of this reaction. The details of equations' derivation are mentioned in the Supporting Information (SI, Equations (S17)-(S25)).

\subsection{Chain Transfer to a Solvent}

A secondary radical $\left(R_{n}^{* *}\right)$ can abstract a hydrogen from a solvent molecule $(S)$ to generate a dead polymer chain $\left(D_{n}\right)$ and an active solvent-based radical $\left(R_{0}^{*}\right)$ :

$$
R_{n}^{* *}+S \stackrel{k_{t r, s}}{\rightarrow} D_{n}+R_{0}^{*}
$$

Solvents are usually added to polymerization media to decrease the viscosity build up upon monomer to polymer conversion and to obviate its consequences like gel and glass effects. Their presence in the reaction media lowers average molecular weights, if the rates of their chain-transfer-to-solvent reactions are appreciable. The extent of chain transfer to solvent varies from one solvent to another, and is usually described with a dimension-less number called the transfer to solvent constant [53]:

$$
C_{t r, s}=\frac{k_{t r, s}}{k_{p}}
$$

where $k_{t r, s}$ and $k_{p}$ are rate coefficients of transfer to solvent and propagation reactions, respectively.

The following rate equations describe the contributions of this reaction to the production and consumption of different species as well as the relevant moments:

$$
\begin{gathered}
r_{s}=-k_{t r, s}[S] \rho_{0}^{* *} \\
r_{R_{0}^{*}}=k_{t r, s}[S] \rho_{0}^{* *} \\
r_{R_{1}^{* *}}=-k_{t r, s}[S]\left[R_{1}^{* *}\right] \\
r_{R_{2}^{* *}}=-k_{t r, s}[S]\left[R_{2}^{* *}\right] \\
r_{\rho_{0}^{* *}}=-k_{t r, s}[S] \rho_{0}^{* *} \\
r_{\rho_{1}^{* *}}=-k_{t r, s}[S] \rho_{1}^{* *} \\
r_{\rho_{2}^{* *}}=-k_{t r, s}[S] \rho_{2}^{* *} \\
r_{\delta_{0}}=k_{t r, s}[S] \rho_{0}^{* *} \\
r_{\delta_{1}}=k_{t r, s}[S] \rho_{1}^{* *} \\
r_{\delta_{2}}=k_{t r, s}[S] \rho_{2}^{* *}
\end{gathered}
$$

Tertiary radicals of types $R_{n}^{* * *}$ and $\widetilde{R}_{n}^{* * * *}$ can also abstract a hydrogen from a solvent molecule to form a dead polymer chain and an active solvent-based radical. The contributions of these reactions to the production and consumption of different species as well as the relevant moments are shown in SI, Equations (S26)-(S45).

$$
R_{n}^{* * *}+S \stackrel{k_{t r, s}^{t}}{\rightarrow} D_{n}+R_{0}^{*}
$$




$$
\widetilde{R}_{n}^{* * *}+S \stackrel{k_{t r s s}^{t}}{\rightarrow} D_{n}+R_{0}^{*}
$$

\subsection{Chain Transfer to a Monomer}

A secondary radical can abstract a hydrogen from a monomer molecule, leading to the termination of the secondary radical and the generation of a new secondary radical with one monomer unit [54]:

$$
R_{n}^{* *}+M \stackrel{k_{\text {tr }, m}}{\rightarrow} D_{n}+R_{1}^{* *}
$$

Unlike propagation reactions, this reaction generates a saturated dead polymer chain and a monoradical with one-monomer-unit length. Like transfer to solvent constants, transfer to monomer constants, $C_{t r, m}=k_{t r, m} / k_{p}$ values, have been reported for different monomers. The following rate equations describe the contributions of this reaction to the production and consumption of different species as well as the relevant moments:

$$
\begin{gathered}
r_{R_{0}^{*}}=-k_{t r, M}[M]\left[R_{0}^{*}\right] \\
r_{R_{1}^{* *}}=k_{t r, M}[M] \rho_{0}^{* *}-k_{t r, M}[M]\left[R_{1}^{* *}\right] \\
r_{R_{2}^{* *}}=-k_{t r, M}[M]\left[R_{2}^{* *}\right] \\
r_{M}=-k_{t r, M}[M] \rho_{0}^{* *} \\
r_{\rho_{0}^{* *}}=0 \\
r_{\rho_{1}^{* *}}=k_{t r, M}[M]\left(\rho_{0}^{* *}-\rho_{1}^{* *}\right) \\
r_{\rho_{2}^{* *}}=k_{t r, M}[M]\left(\rho_{0}^{* *}-\rho_{2}^{* *}\right) \\
r_{\delta_{0}}=k_{t r, M}[M] \rho_{0}^{* *} \\
r_{\delta_{1}}=k_{t r, M}[M] \rho_{1}^{* *} \\
r_{\delta_{2}}=k_{t r, M}[M] \rho_{2}^{* *}
\end{gathered}
$$

This reaction should does not change the total number of monomer units in the system; $r_{M}+r_{\rho_{1}^{* *}}$ $+r_{\delta_{1}}=0$ holds. As shown below, tertiary radicals can also participate in chain transfer to monomer reactions. The contributions of these reactions to the production and consumption of different species as well as the relevant moments are presented in SI (Equations (S46)-(S65)).

$$
\begin{aligned}
& R_{n}^{* * *}+M \stackrel{k_{t r, M}^{t}}{\rightarrow} D_{n}+R_{1}^{* *} \\
& \widetilde{R}_{n}^{* * *}+M \stackrel{k_{t r, M}^{t}}{\rightarrow} D_{n}+R_{1}^{* *}
\end{aligned}
$$

\subsection{Chain Transfer from a Radical to a Dead Polymer Chain}

A secondary radical can abstract a hydrogen from a dead polymer chain, leading to the formation of a new dead polymer chain and a new tertiary radical of type $R_{n}^{* * *}$ :

$$
R_{n}^{* *}+D_{m} \stackrel{m k_{t r,}, P}{\rightarrow} D_{n}+R_{m}^{* * *}
$$

An important point here is that every monomer unit in the dead polymer chain has the chance to be attacked by the macroradical. Thus, we need to multiply the transfer to polymer rate coefficient by the number of monomer units of the reactant dead chain. The following rate equations describe the 
contributions of this reaction to the production and consumption of different species as well as the relevant moments:

$$
\begin{gathered}
r_{R_{0}^{*}}=-k_{t r, P}\left[R_{0}^{*}\right] \delta_{1} \\
r_{R_{1}^{* *}}=-k_{t r, P}\left[R_{1}^{* *}\right] \delta_{1} \\
r_{R_{2}^{* *}}=-k_{t r, P}\left[R_{2}^{* *}\right] \delta_{1} \\
r_{\rho_{0}^{* *}}=-k_{t r, P} \rho_{0}^{* *} \delta_{1} \\
r_{\rho_{1}^{* *}}=-k_{t r, P} \rho_{1}^{* *} \delta_{1} \\
r_{\rho_{2}^{* *}}=-k_{t r, P} \rho_{2}^{* *} \delta_{1} \\
r_{\rho_{0}^{* * *}}=k_{t r, P} \rho_{0}^{* *} \delta_{1} \\
r_{\rho_{1}^{* * *}}=k_{t r, P} \rho_{0}^{* *} \delta_{2} \\
r_{\rho_{2}^{* * *}}=k_{t r, P} \rho_{0}^{* *} \delta_{3} \\
r_{\delta_{0}}=0 \\
r_{\delta_{1}}=-k_{t r, P} \rho_{0}^{* *} \delta_{2}+k_{t r, P} \delta_{1} \rho_{1}^{* *} \\
r_{\delta_{2}}=-k_{t r, P} \rho_{0}^{* *} \delta_{3}+k_{t r, P} \delta_{1} \rho_{2}^{* *}
\end{gathered}
$$

Again, this reaction does not change the total population of monomers in the system, as $r_{\rho_{1}^{* *}}+$ $r_{\rho_{1}^{* * *+}}+r_{\delta_{1}}=0$. Equations (129) and (132) indicate that $r_{\delta_{2}}$ and $r_{\rho_{2}^{* * *}}$ depend on $\delta_{3}$, which implies that the value of $\delta_{3}$ is needed to calculate $\delta_{2}$. To address this closure problem, a CLD model should be assumed for the saturated dead polymer chains, which allows one to describe the third moment of the distribution based on the lower moments of the same distribution [55]. For example, based on:

- A re-scaled Gamma distribution [9]:

$$
\delta_{3}=\left(\frac{\delta_{2}}{\delta_{0} \delta_{1}}\right)\left(2 \delta_{0} \delta_{2}-\delta_{1}^{2}\right)
$$

- A log-normal distribution [55]:

$$
\delta_{3}=\delta_{0}\left(\frac{\delta_{2}^{3}}{\delta_{1}}\right)
$$

- A Gaussian distribution [9]:

$$
\delta_{3}=3 \delta_{1} \delta_{2}-\delta_{1}^{3}
$$

Similar to the secondary radicals, tertiary radicals of types $R_{n}^{* * *}$ and $\widetilde{R}_{n}^{* * *}$ can attack dead polymer chains to abstract a hydrogen as shown below. The contributions of these reactions to the production and consumption of different species as well as the relevant moments are presented in SI, Equations (S66)-(S82).

$$
\begin{aligned}
& R_{n}^{* * *}+D_{m} \stackrel{m k_{t r, p}^{t}}{\rightarrow} D_{n}+R_{m}^{* * *} \\
& \widetilde{R}_{n}^{* * *}+D_{m} \stackrel{m k_{t r, P}^{t}}{\rightarrow} D_{n}+R_{m}^{* * *}
\end{aligned}
$$

\subsection{Chain Transfer from a Radical to a Macromonomer}

A secondary radical can react with a macromonomer, leading to the formation of a dead saturated chain and a tertiary radical of type $R_{m}^{* * *}$ :

$$
R_{n}^{* *}+U_{m} \stackrel{(m-1) k_{t r, P}}{\rightarrow} D_{n}+R_{m}^{* * *}
$$


As the abstraction of a hydrogen from an unsaturated carbon double bond is difficult, we consider $(m-1)$ sites for hydrogen abstraction from the macromonomer. This is the reason that the rate coefficient of this reaction is multiplied to $(m-1)$. The following rate equations describe the contributions of this reaction to the production and consumption of different species as well as the relevant moments:

$$
\begin{aligned}
& r_{R_{1}^{* *}}=-k_{t r, P}\left[R_{1}^{* *}\right]\left(\epsilon_{1}-\epsilon_{0}\right) \\
& r_{R_{2}^{* *}}=-k_{t r, P}\left[R_{2}^{* *}\right]\left(\epsilon_{1}-\epsilon_{0}\right) \\
& r_{\rho_{0}^{* *}}=-k_{t r, P} \rho_{0}^{* *}\left(\epsilon_{1}-\epsilon_{0}\right) \\
& r_{\rho_{1}^{* *}}=-k_{t r, P} \rho_{1}^{* *}\left(\epsilon_{1}-\epsilon_{0}\right) \\
& r_{\rho_{2}^{* *}}=-k_{t r, P} \rho_{2}^{* *}\left(\epsilon_{1}-\epsilon_{0}\right) \\
& r_{\rho_{0}^{* * *}}=k_{t r, P} \rho_{0}^{* *}\left(\epsilon_{1}-\epsilon_{0}\right) \\
& r_{\rho_{1}^{* * *}}=k_{t r, P} \rho_{0}^{* *}\left(\epsilon_{2}-\epsilon_{1}\right) \\
& r_{\rho_{2}^{* * *}}=k_{t r, P} \rho_{0}^{* *}\left(\epsilon_{3}-\epsilon_{2}\right) \\
& r_{\delta_{0}}=k_{t r, P} \rho_{0}^{* *}\left(\epsilon_{1}-\epsilon_{0}\right) \\
& r_{\delta_{1}}=k_{t r, P} \rho_{1}^{* *}\left(\epsilon_{1}-\epsilon_{0}\right) \\
& r_{\delta_{2}}=k_{t r, P} \rho_{2}^{* *}\left(\epsilon_{1}-\epsilon_{0}\right) \\
& r_{\epsilon_{0}}=-k_{t r, P} \rho_{0}^{* *}\left(\epsilon_{1}-\epsilon_{0}\right) \\
& r_{\epsilon_{1}}=-k_{t r, P} \rho_{0}^{* *}\left(\epsilon_{2}-\epsilon_{1}\right) \\
& r_{\epsilon_{2}}=-k_{t r, P} \rho_{0}^{* *}\left(\epsilon_{3}-\epsilon_{2}\right)
\end{aligned}
$$

The satisfaction of $r_{\rho_{1}^{* *}}+r_{\rho_{1}^{* * *}}+r_{\delta_{1}}+r_{\epsilon_{1}}=0$, verifies that this reaction does not change the total number of monomer units in the system. Tertiary radicals are also capable of attacking macromonomers to abstract a hydrogen as shown below. The contributions of these reactions to the production and consumption of different species as well as the relevant moments are presented in the SI, Equations (S83)-(S105).

$$
\begin{aligned}
& R_{n}^{* * *}+U_{m} \stackrel{(m-1) k_{t r, p}^{t}}{\rightarrow} D_{n}+R_{m}^{* * *} \\
& \widetilde{R}_{n}^{* * *}+U_{m} \stackrel{(m-1) k_{t r, p}^{t}}{\rightarrow} D_{n}+R_{m}^{* * *}
\end{aligned}
$$

\subsection{Termination by Combination of a Secondary Radical Type $R_{n}^{* *}$}

A secondary radical can react with another secondary radical, forming a saturated dead polymer chain that includes the monomer units of both radicals:

$$
R_{n}^{* *}+R_{m}^{* *} \stackrel{k_{t c}}{\rightarrow} D_{n+m}
$$

The reaction creates a carbon-carbon bond between the radical-bearing carbons of the two living chains. The following rate equations describe the contributions of this reaction to the production and consumption of different species as well as the relevant moments:

$$
\begin{aligned}
& r_{R_{0}^{*}}=-k_{t c}\left[R_{0}^{*}\right] \rho_{0}^{* *} \\
& r_{R_{1}^{* *}}=-k_{t c}\left[R_{1}^{* *}\right] \rho_{0}^{* *} \\
& r_{R_{2}^{* *}}=-k_{t c}\left[R_{2}^{* *}\right] \rho_{0}^{* *}
\end{aligned}
$$




$$
\begin{gathered}
r_{\rho_{0}^{* *}}=-k_{t c} \rho_{0}^{* 2^{2}} \\
r_{\rho_{1}^{* *}}=-k_{t c} \rho_{0}^{* *} \rho_{1}^{* *} \\
r_{\rho_{2}^{* *}}=-k_{t c} \rho_{0}^{* *} \rho_{2}^{* *} \\
r_{\delta_{0}}=\frac{1}{2} k_{t c} \rho_{0}^{* *^{2}} \\
r_{\delta_{1}}=k_{t c} \rho_{0}^{* *} \rho_{1}^{* *} \\
r_{\delta_{2}}=k_{t c}\left(\rho_{0}^{* *} \rho_{2}^{* *}+\rho_{1}^{* 2^{2}}\right)
\end{gathered}
$$

Here, $r_{\rho_{1}^{* *}}+r_{\delta_{1}}=0$, which confirms that this reaction does not change the total number of monomer units. A secondary radical can also react with a tertiary radical of type $R_{m}^{* * *}$ or $\widetilde{R}_{m}^{* * *}$ :

$$
\begin{aligned}
& R_{n}^{* *}+R_{m}^{* * *} \stackrel{2 k_{t c}^{t}}{\rightarrow} D_{n+m} \\
& R_{n}^{* *}+\widetilde{R}_{m}^{* * *} \stackrel{2 k_{t c}^{t}}{\rightarrow} D_{n+m}
\end{aligned}
$$

The contributions of these reactions to the production and consumption of different species as well as the relevant moments are presented in the SI, Equations (S106)-(S131).

\subsection{Termination by Combination of a Tertiary Radical Type $R_{n}^{* * *}$}

A radical of this kind can react with a secondary radical, which was consider in (165). It can also react with a tertiary radical of the same type $R_{m}^{* * *}$ to form a saturated dead polymer chain that includes the monomer units of both radicals:

$$
R_{n}^{* * *}+R_{m}^{* * *} \stackrel{k_{t c}^{t t}}{\rightarrow} D_{n+m}
$$

The rate coefficient of this reaction is smaller than that of the reaction of (155) as both reacting centers have tertiary carbons [9]. The following rate equations describe the contributions of this reaction to the production and consumption of different species as well as the relevant moments:

$$
\begin{gathered}
r_{\rho_{0}^{* * *}}=-k_{t c}^{t t} \rho_{0}^{* * * *^{2}} \\
r_{\rho_{1}^{* * *}}=-k_{t c}^{t t} \rho_{0}^{* * *} \rho_{1}^{* * *} \\
r_{\rho_{2}^{* * * *}}=-k_{t c}^{t t} \rho_{0}^{* * *} \rho_{2}^{* * *} \\
r_{\delta_{0}}=\frac{1}{2} k_{t c}^{t t} \rho_{0}^{* * 2^{2}} \\
r_{\delta_{1}}=k_{t c}^{t t} \rho_{0}^{* * *} \rho_{1}^{* * *} \\
r_{\delta_{2}}=k_{t c}^{t t}\left(\rho_{0}^{* * *} \rho_{2}^{* * *}+\rho_{1}^{* * 2^{2}}\right)
\end{gathered}
$$

The sum of the first moments is zero, confirming no change in the total number of monomer units upon the occurrence of this reaction.

A tertiary radical type $R_{n}^{* * *}$ can also react with a radical of type $\widetilde{R}_{m}^{* * *}$ :

$$
R_{n}^{* * *}+\widetilde{R}_{m}^{* * *} \stackrel{2 k_{t c}^{t t}}{\rightarrow} D_{n+m}
$$

The rate equations describing the contributions of this reaction to the production and consumption of different species as well as the relevant moments are presented in SI, Equations (S132)-(S141). 


\subsection{Termination by Combination of a Tertiary Radical Type $\widetilde{R}_{m}^{* * *}$}

For this radical, two possible termination reactions with $R_{n}^{* *}$ and $R_{n}^{* * *}$ were discussed in Sections 2.13 and 2.14. The third possible termination by combination reaction is that of two tertiary radicals of the type $\widetilde{R}_{n}^{* * *}$ :

$$
\widetilde{R}_{n}^{* * *}+\widetilde{R}_{m}^{* * *} \stackrel{k_{t c}^{t t}}{\rightarrow} D_{n+m}
$$

The following rate equations describe the contributions of this reaction to the production and consumption of different species as well as the relevant moments:

$$
\begin{aligned}
& r_{\widetilde{\rho}_{0}^{* * *}}=-k_{t c}^{t t} \widetilde{\rho}_{0}^{* * *^{2}} \\
& r_{\widetilde{\rho}_{1}^{* * *}}=-k_{t c}^{t t} \widetilde{\rho}_{0}^{* * *} \widetilde{\rho}_{1}^{* * *} \\
& r_{\bar{\rho}_{2}^{* * *}}=-k_{t c}^{t t} \widetilde{\rho}_{0}^{* * *} \widetilde{\rho}_{2}^{* * *} \\
& r_{\delta_{0}}=\frac{1}{2} k_{t c}^{t t} \widetilde{\rho}_{0}^{* * 2^{2}} \\
& r_{\delta_{1}}=k_{t c}^{t t}\left(\widetilde{\rho}_{1}^{* * *} \widetilde{\rho}_{0}^{* * *}\right) \\
& r_{\delta_{2}}=k_{t c}^{t t}\left(\vec{\rho}_{2}^{* * *} \vec{\rho}_{0}^{* * *}+\widetilde{\rho}_{1}^{* *{ }^{2}}\right)
\end{aligned}
$$

Here, as expected, the sum of the first moments equals to zero.

\subsection{Termination by Disproportionation of a Secondary Radical Type $R_{n}^{* *}$}

Two secondary radicals can participate in a disproportionation termination reaction in which one radical abstracts a hydrogen from the other radical, leading to the formation of one saturated and one unsaturated dead chain:

$$
\begin{aligned}
& R_{n}^{* *}+R_{m}^{* *} \stackrel{k_{t d}}{\rightarrow} D_{n}+U_{m} \\
& R_{n}^{* *}+R_{m}^{* *} \stackrel{k_{t d}}{\rightarrow} D_{m}+U_{n}
\end{aligned}
$$

The only difference between these two reactions is in the lengths (number of monomer units) of the produced dead polymer chains, which depends on which radical abstracts the hydrogen. The following rate equations describe the contributions of these two reactions to the production and consumption of different species as well as the relevant moments:

$$
\begin{gathered}
r_{R_{0}^{*}}=-2 k_{t d}\left[R_{0}^{*}\right] \rho_{0}^{* *} \\
r_{R_{1}^{* *}}=-2 k_{t d}\left[R_{1}^{* *}\right] \rho_{0}^{* *} \\
r_{R_{2}^{* *}}=-2 k_{t d}\left[R_{2}^{* *}\right] \rho_{0}^{* *} \\
r_{\rho_{0}^{* *}}=-2 k_{t d} \rho_{0}^{* *^{2}} \\
r_{\rho_{1}^{* *}}=-2 k_{t d} \rho_{0}^{* *} \rho_{1}^{* *} \\
r_{\rho_{2}^{* *}}=-2 k_{t d} \rho_{0}^{* *} \rho_{2}^{* *} \\
r_{\delta_{0}}=r_{\epsilon_{0}}=k_{t d} \rho_{0}^{*{ }^{2}} \\
r_{\delta_{1}}=r_{\epsilon_{1}}=k_{t d} \rho_{0}^{* *} \rho_{1}^{* *} \\
r_{\delta_{2}}=r_{\epsilon_{2}}=k_{t d} \rho_{0}^{* *} \rho_{2}^{* *}
\end{gathered}
$$


The sum of the rates of the first moments, $r_{\delta_{1}}+r_{\epsilon_{1}}+r_{\rho_{1}^{* *}}$, equals to zero, confirming that these two reactions do not change the total number of monomer units in the system. Other disproportionation termination pathways for a secondary radical are shown below:

$$
\begin{aligned}
& R_{n}^{* *}+R_{m}^{* * *} \stackrel{k_{t d}^{t}}{\rightarrow} D_{n}+U_{m} \\
& R_{n}^{* *}+R_{m}^{* * *} \stackrel{k_{t d}^{t}}{\rightarrow} D_{m}+U_{n} \\
& R_{n}^{* *}+\widetilde{R}_{m}^{* * *} \stackrel{k_{t d}^{t}}{\rightarrow} D_{m}+U_{n} \\
& R_{n}^{* *}+\widetilde{R}_{m}^{* * *} \stackrel{k_{t d}^{t}}{\rightarrow} D_{n}+U_{m}
\end{aligned}
$$

The contributions of each of these reactions to the production and consumption of different species as well as the relevant moments are presented in SI, Equations (S142)-(S185).

\subsection{Termination by Disproportionation of a Tertiary Radical Type $R_{m}^{* * *}$}

A tertiary radical $R_{n}^{* * *}$ can react with a secondary radical, as discussed in the previous section. It can also react with another tertiary radical of the same type. One radical abstracts a hydrogen from the other radical, leading to the formation of a saturated and an unsaturated dead chain:

$$
\begin{aligned}
& R_{n}^{* * *}+R_{m}^{* * *} \stackrel{\stackrel{k t d}{\rightarrow}}{\rightarrow t} D_{n}+U_{m} \\
& R_{n}^{* * *}+R_{m}^{* * *} \stackrel{k_{t d}^{t t}}{\rightarrow} D_{m}+U_{n}
\end{aligned}
$$

The following rate equations describe the contributions of these reactions to the production and consumption of different species as well as the relevant moments:

$$
\begin{gathered}
r_{\rho_{0}^{* * *}}=-2 k_{t d}^{t t} \rho_{0}^{* * *^{2}} \\
r_{\rho_{1}^{* * *}}=-2 k_{t d}^{t t} \rho_{0}^{* * *} \rho_{1}^{* * *} \\
r_{\rho_{2}^{* * *}}=-2 k_{t d}^{t t} \rho_{0}^{* * *} \rho_{2}^{* * *} \\
r_{\delta_{0}}=r_{\epsilon_{0}}=k_{t d}^{t t} \rho_{0}^{* * * *^{2}} \\
r_{\delta_{1}}=r_{\epsilon_{1}}=k_{t d}^{t t} \rho_{1}^{* * *} \rho_{0}^{* * *} \\
r_{\delta_{2}}=r_{\epsilon_{2}}=k_{t d}^{t t} \rho_{2}^{* * *} \rho_{0}^{* * *}
\end{gathered}
$$

Here, $r_{\rho_{1}^{* * *}}+r_{\delta_{1}}+r_{\epsilon_{1}}=0$ confirms that these reactions do not change the total number of monomer units in the system.

A tertiary radical $R_{n}^{* * *}$ can also react with a tertiary radical of the type $\widetilde{R}_{n}^{* * *}$.

$$
\begin{aligned}
& \widetilde{R}_{n}^{* * *}+R_{m}^{* * *} \stackrel{k_{t d}^{t t}}{\rightarrow} D_{m}+U_{n} \\
& \widetilde{R}_{n}^{* * *}+R_{m}^{* * *} \stackrel{k_{t d}^{t t}}{\rightarrow} D_{n}+U_{m}
\end{aligned}
$$

The contributions of the reaction to the production and consumption of different species as well as the relevant moments are presented in SI, Equations (S186)-(S204). 
2.18. Termination by Disproportionation of a Tertiary Radical Type $\widetilde{R}_{m}^{* * *}$

A tertiary radical type $\widetilde{R}_{m}^{* * *}$ can react with $R_{n}^{* *}$ and $R_{n}^{* * *}$, which were discussed before. It can also react with a tertiary radical of the same type. One radical abstracts a hydrogen from the other radical, leading to the formation of a saturated and an unsaturated dead chain:

$$
\begin{gathered}
\widetilde{R}_{n}^{* * *}+\widetilde{R}_{m}^{* * *} \stackrel{k_{t d}^{t t}}{\rightarrow} D_{n}+U_{m} \\
\widetilde{R}_{n}^{* * *}+\widetilde{R}_{m}^{* * *} \stackrel{k_{t d}^{t t}}{\rightarrow} D_{m}+U_{n}
\end{gathered}
$$

The following rate equations describe the contributions of these reactions to the production and consumption of different species as well as the relevant moments:

$$
\begin{aligned}
& r_{\widetilde{\rho}_{0}^{* * *}}=-2 k_{t d}^{t t} \tilde{\rho}_{0}^{* * *} \tilde{\rho}_{0}^{* * *} \\
& r_{\widetilde{\rho}_{1}^{* * *}}=-2 k_{t d}^{t t} \tilde{\rho}_{1}^{* * *} \tilde{\rho}_{0}^{* * *} \\
& r_{\widetilde{\rho}_{2}^{* * *}}=-2 k_{t d}^{t t} \tilde{\rho}_{2}^{* * *} \widetilde{\rho}_{0}^{* * *} \\
& r_{\delta_{0}}=r_{\epsilon_{0}}=k_{t d}^{t t} \widetilde{\rho}_{0}^{* * *} \widetilde{\rho}_{0}^{* * *} \\
& r_{\delta_{1}}=r_{\epsilon_{1}}=k_{t d}^{t t} \widetilde{\rho}_{1}^{* * *} \widetilde{\rho}_{0}^{* * *} \\
& r_{\delta_{2}}=r_{\epsilon_{2}}=k_{t d}^{t t} \widetilde{\rho}_{2}^{* * *} \widetilde{\rho}_{0}^{* * *}
\end{aligned}
$$

\subsection{Propagation of Radicals by Reacting with a Macromonomer}

In this reaction, a secondary radical reacts with a dead unsaturated chain, leading to the production of a tertiary radical of the type $R_{n}^{* * *}$ containing all monomer units of the dead polymer chain and the secondary radical:

$$
R_{n}^{* *}+U_{m} \stackrel{k_{m a c}}{\longrightarrow} R_{n+m}^{* * *}
$$

The following rate equations describe the contributions of this reaction to the production and consumption of different species as well as the relevant moments:

$$
\begin{gathered}
r_{R_{0}^{*}}=-k_{m a c}\left[R_{0}^{*}\right] \epsilon_{0} \\
r_{R_{1}^{* *}}=-k_{m a c}\left[R_{1}^{* *}\right] \epsilon_{0} \\
r_{R_{2}^{* *}}=-k_{m a c}\left[R_{2}^{* *}\right] \epsilon_{0} \\
r_{\rho_{0}^{* *}}=-k_{m a c} \rho_{0}^{* *} \epsilon_{0} \\
r_{\rho_{1}^{* *}}=-k_{m a c} \rho_{1}^{* *} \epsilon_{0} \\
r_{\rho_{2}^{* *}}=-k_{m a c} \rho_{2}^{* *} \epsilon_{0} \\
r_{\rho_{0}^{* * *}}=k_{m a c} \rho_{0}^{* *} \epsilon_{0} \\
r_{\rho_{1}^{* * *}}=k_{m a c}\left(\rho_{1}^{* *} \epsilon_{0}+\rho_{0}^{* *} \epsilon_{1}\right) \\
r_{\rho_{2}^{* * * *}}=k_{m a c}\left(\rho_{2}^{* *} \epsilon_{0}+\rho_{0}^{* *} \epsilon_{2}+2 \rho_{1}^{* *} \epsilon_{1}\right) \\
r_{\epsilon_{0}}=-k_{m a c} \rho_{0}^{* *} \epsilon_{0} \\
r_{\epsilon_{1}}=-k_{m a c} \rho_{0}^{* *} \epsilon_{1} \\
r_{\epsilon_{2}}=-k_{\text {mac }} \rho_{0}^{* *} \epsilon_{2}
\end{gathered}
$$


These rate equations satisfy $r_{\rho_{1}^{* *}}+r_{\rho_{1}^{* * *}}+r_{\epsilon_{1}}=0$, confirming that this reaction does not change the total number of monomer units. Tertiary radicals of types $R_{n}^{* * *}$ and $\widetilde{R}_{n}^{* * *}$ can also attack dead unsaturated chains to propagate and form longer-branched growing chains.

$$
\begin{aligned}
& R_{n}^{* * *}+U_{m} \stackrel{k_{m a c}^{t}}{\rightarrow} R_{n+m}^{* * *} \\
& \widetilde{R}_{n}^{* * *}+U_{m} \stackrel{k_{m a c}^{t}}{\rightarrow} R_{n+m}^{* * *}
\end{aligned}
$$

The equations describing the contributions of these reactions to the production and consumption of different species as well as the relevant moments are presented in SI, Equations (S205)-(S221).

\section{Overall Rate Equations}

After considering primary and secondary reactions that are most likely to occur in high-temperature free-radical polymerization and determining the contributions of each reaction to the production of each species and each CLD moment, one needs to obtain all overall rate equations. The overall rate equation for the production of a species (or a CLD moment of a class of polymer chains) is the sum of the rate equations of the production of the species (or the CLD moment of the class of polymer chains in all reactions). For example, the overall rate of production of $M$ is the sum of the individual $r_{M}{ }^{\prime} \mathrm{s}$ given in Equations (10), (18), (29), (38), and (111), Equations (S2), (S10), (S48) and (S58).

\section{Case Study: High-Temperature Free-Radical Polymerization of Methyl Acrylate (MA)}

The derived rate equations are used in an MA batch polymerization reactor model to predict monomer conversion and polymer average molecular weights at 180 and $200{ }^{\circ} \mathrm{C}$. The details of the experimental study can be found in Ref. [5]. Measurements of monomer conversion and polymer average molecular weights made, respectively, with the gravimetry method and a gel-permeation chromatograph are compared with the same model-predicted polymer properties.

Different rate coefficients for $n$-butyl acrylate $(n \mathrm{BA})$ propagation, transfer to polymer, backbiting, $\beta$-Scission, transfer to monomer, and termination reactions have been reported in the literature (Table S2) $[5,9,45,56-69]$. On the other hand, a reliable experimentally determined MA propagation rate coefficient is available [45]. On the basis of the available $n \mathrm{BA}$ and the reliable experimentally determined MA rate coefficients and using the family-type-behavior approach [45] (explained in Section (20) of the SI), we determined ranges for the activation energies and frequency factors of backbiting and $\beta$-scission reactions of MA. The monomer self-initiation rate coefficient reported in Ref. [5] was used here. Other rate coefficients used in this study are reported in Table S4.

After determining the ranges, the genetic algorithm ( $g a$ ) optimizer [70] of MATLAB was used to estimate the activation energies and frequency factors of backbiting and $\beta$-scission reactions within the ranges and parameters of a gel effect model [5], from monomer conversion and average molecular weights measurements. The estimated values are presented in Table 1. Figure 3 compares model predictions and measurements of MA conversion, number-average molecular weight, and weight-average molecular weight. It shows a good agreement between the model predictions and measurements.

Table 1. Estimates of methyl acrylate (MA) reaction kinetic parameters obtained in this work (activation energies, $\mathrm{kJ} \mathrm{mol}^{-1} ; R, \mathrm{~J} \mathrm{~mol}^{-1} \mathrm{~K}^{-1}$ ).

\begin{tabular}{cc}
\hline Reaction & Rate Coefficient \\
\hline Backbiting $\left(\mathrm{s}^{-1}\right)$ & $k_{b b}=2.01 \times 10^{10} \exp \left(\frac{-51.03}{R T}\right)$ \\
$\beta$-Scission $\left(\mathrm{s}^{-1}\right)$ & $k_{\beta}=3.67 \times 10^{14} \exp \left(\frac{-97.90}{R T}\right)$ \\
\hline
\end{tabular}



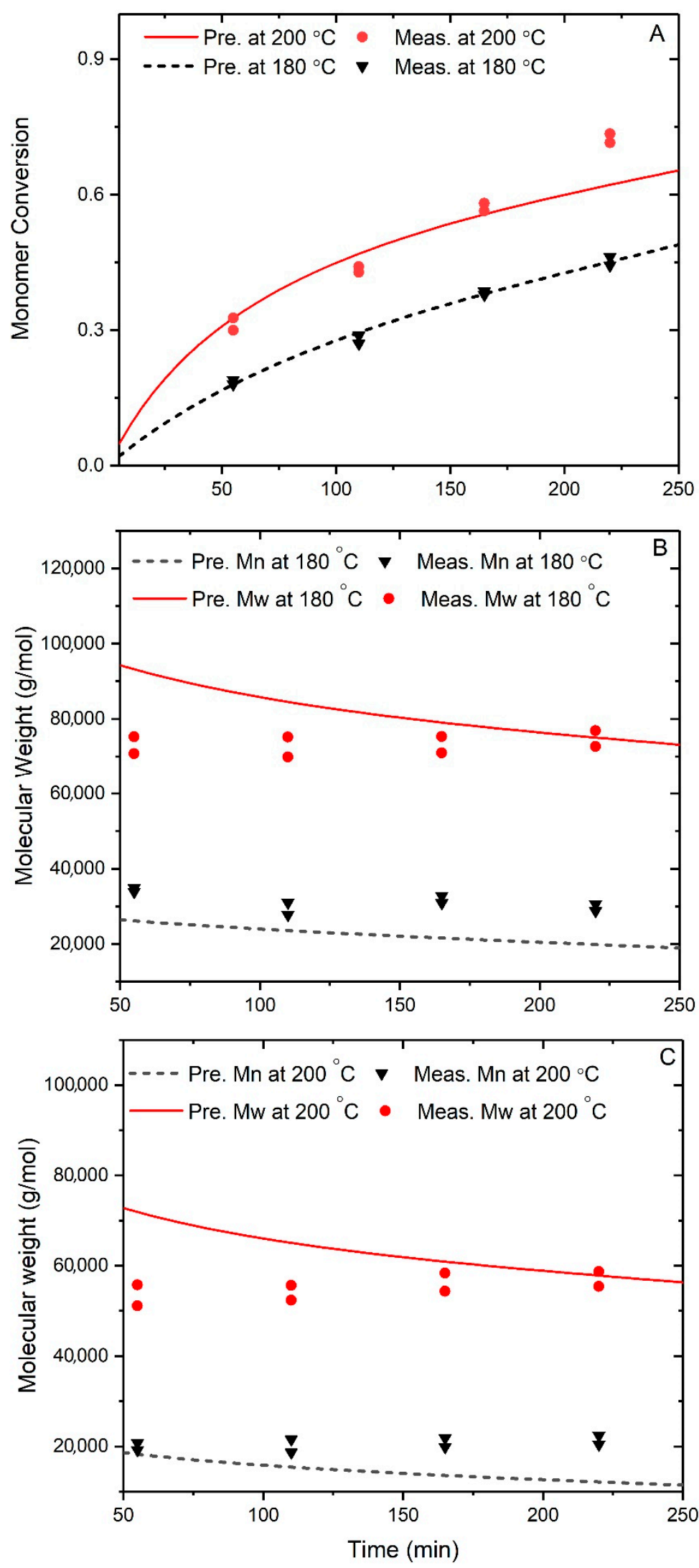

Figure 3. (A-C) Comparing model predictions and measurements of monomer conversion, number average molecular weight (Mn) and weight average molecular weight $(\mathrm{Mw})$ at $180^{\circ} \mathrm{C}$ and $200{ }^{\circ} \mathrm{C}$. 


\section{Conclusions}

Most-likely reactions that occur in free-radical polymerization of acrylates were considered. This article provides a systematic approach to account for the contributions of each reaction to the production or consumption of each species and to the rates of the moments of chain-length distributions of different polymer types. Three types of free radicals and two types of dead polymers were considered. The closure problems were addressed by assuming a model for each CLD that is affected. Using the systematic approach proposed herein, one can easily derive rate equations that are not considered in this article. Finally, to show the application of the rate equations, they were used in a batch polymerization reactor model that simulates high-temperature bulk free-radical polymerization of MA. The kinetic parameters of the backbiting and $\beta$-scission reactions were estimated from measurements of monomer conversion and number- and weight-average molecular weights.

Supplementary Materials: The following are available online at http://www.mdpi.com/2227-9717/7/10/656/s1.

Author Contributions: M.S. and H.R. derived the rate equations and prepared the first draft of this paper. H.R. did the polymerization reactions and A.A.S. measured molecular weights. M.C.G. contributed to the design of the experiments and data analysis. A.M.R. contributed to the design of the experiments and the preparation of this manuscript.

Funding: This material is based upon work supported by the U.S. National Science Foundation under Grant Nos. CBET-1804285 and CBET-1803215. Any opinions, findings, and conclusions or recommendations expressed in this material are those of the authors and do not necessarily reflect the views of the National Science Foundation.

Conflicts of Interest: The authors declare no conflict of interest.

\section{References}

1. Matyjaszewski, K.; Davis, T.P. Handbook of Radical Polymerization; John Wiley \& Sons: Hoboken, NJ, USA, 2003.

2. Riazi, H.; Mohammadi, N.; Mohammadi, H. Emulsion copolymerization of methyl methacrylate/butyl acrylate/iodine system to monosize rubbery nanoparticles containing iodine and triiodide mixture. Ind. Eng. Chem. Res. 2013, 52, 2449-2456. [CrossRef]

3. Adelnia, H.; Riazi, H.; Saadat, Y.; Hosseinzadeh, S. Synthesis of monodisperse anionic submicron polystyrene particles by stabilizer-free dispersion polymerization in alcoholic media. Colloid Polym. Sci. 2013, 291, 1741-1748. [CrossRef]

4. Campbell, J.; Teymour, F.; Morbidelli, M. High temperature free radical polymerization. 1. Investigation of continuous styrene polymerization. Macromolecules 2003, 36, 5491-5501. [CrossRef]

5. Riazi, H.; Shamsabadi, A.A.; Grady, M.C.; Rappe, A.M.; Soroush, M. Experimental and Theoretical Study of the Self-Initiation Reaction of Methyl Acrylate in Free-Radical Polymerization. Ind. Eng. Chem. Res. 2018, 57, 532-539. [CrossRef]

6. Riazi, H.; Shamsabadi, A.; Corcoran, P.; Grady, M.; Rappe, A.; Soroush, M. On the Thermal Self-Initiation Reaction of n-Butyl Acrylate in Free-Radical Polymerization. Processes 2018, 6, 3. [CrossRef]

7. Khuong, K.S.; Jones, W.H.; Pryor, W.A.; Houk, K. The mechanism of the self-initiated thermal polymerization of styrene. Theoretical solution of a classic problem. J. Am. Chem. Soc. 2005, 127, 1265-1277. [CrossRef] [PubMed]

8. Srinivasan, S.; Kalfas, G.; Petkovska, V.I.; Bruni, C.; Grady, M.C.; Soroush, M. Experimental study of the spontaneous thermal homopolymerization of methyl and n-butyl acrylate. J. Appl. Polym. Sci. 2010, 118, 1898-1909. [CrossRef]

9. Arabi Shamsabadi, A.; Moghadam, N.; Srinivasan, S.; Corcoran, P.; Grady, M.; Rappe, A.; Soroush, M. Study of n-Butyl Acrylate Self-Initiation Reaction Experimentally and via Macroscopic Mechanistic Modeling. Processes 2016, 4, 15. [CrossRef]

10. Ballard, N.; Veloso, A.; Asua, J. Mid-Chain Radical Migration in the Radical Polymerization of n-Butyl Acrylate. Polymers 2018, 10, 765. [CrossRef]

11. Ren, S.; Vivaldo-Lima, E.; Dubé, M. Modeling of the Copolymerization Kinetics of n-Butyl Acrylate and D-Limonene Using PREDICI ${ }^{\circledR}$. Processes 2016, 4, 1. [CrossRef] 
12. Villermaux, J.; Blavier, L. Free radical polymerization engineering-I: A new method for modeling free radical homogeneous polymerization reactions. Chem. Eng. Sci. 1984, 39, 87-99. [CrossRef]

13. Mastan, E.; Li, X.; Zhu, S. Modeling and theoretical development in controlled radical polymerization. Prog. Polym. Sci. 2015, 45, 71-101. [CrossRef]

14. Wulkow, M.; Busch, M.; Davis, T.P.; Barner-Kowollik, C. Implementing the reversible addition-fragmentation chain transfer process in PREDICI. J. Polym. Sci. Part A Polym. Chem 2004, 42, 1441-1448. [CrossRef]

15. Gao, H.; Konstantinov, I.A.; Arturo, S.G.; Broadbelt, L.J. On the modeling of number and weight average molecular weight of polymers. Chem. Eng. J. 2017, 327, 906-913. [CrossRef]

16. Soroush, M.; Kravaris, C. Nonlinear control of a batch polymerization reactor: An experimental study. AIChE J. 1992, 38, 1429-1448. [CrossRef]

17. Soroush, M.; Kravaris, C. Optimal design and operation of batch reactors. 2. A case study. Ind. Eng. Chem. Res. 1993, 32, 882-893. [CrossRef]

18. Apostolo, M.; Arcella, V.; Storti, G.; Morbidelli, M. Kinetics of the emulsion polymerization of vinylidene fluoride and hexafluoropropylene. Macromolecules 1999, 32, 989-1003. [CrossRef]

19. Kalfas, G.; Ray, W.H. Modeling and experimental studies of aqueous suspension polymerization processes. 1. Modeling and simulations. Ind. Eng. Chem. Res. 1993, 32, 1822-1830. [CrossRef]

20. Hernández-Barajas, J.; Hunkeler, D.J. Inverse-emulsion polymerization of acrylamide using block copolymeric surfactants: Mechanism, kinetics and modelling. Polymer 1997, 38, 437-447. [CrossRef]

21. Crowley, T.J.; Choi, K.Y. Calculation of molecular weight distribution from molecular weight moments in free radical polymerization. Ind. Eng. Chem. Res. 1997, 36, 1419-1423. [CrossRef]

22. Zhou, Y.N.; Luo, Z.H. An old kinetic method for a new polymerization mechanism: Toward photochemically mediated ATRP. AIChE J. 2015, 61, 1947-1958. [CrossRef]

23. Bonilla, J.; Saldívar, E.; Flores-Tlacuahuac, A.; Vivaldo-Lima, E.; Pfaendner, R.; Tiscareño-Lechuga, F. Detailed modeling, simulation, and parameter estimation of nitroxide mediated living free radical polymerization of styrene. Polym. React. Eng. 2002, 10, 227-263. [CrossRef]

24. Wang, A.R.; Zhu, S. Modeling the reversible addition-fragmentation transfer polymerization process. J. Polym. Sci. Part A Polym. Chem. 2003, 41, 1553-1566. [CrossRef]

25. Mastan, E.; Zhu, S. Method of moments: A versatile tool for deterministic modeling of polymerization kinetics. Eur. Polym. J. 2015, 68, 139-160. [CrossRef]

26. Zhou, Y.N.; Luo, Z.H. State-of-the-art and progress in method of moments for the model-based reversible-deactivation radical polymerization. Macromol. React. Eng. 2016, 10, 516-534. [CrossRef]

27. Bachmann, R.; Melchiors, M.; Avtomonov, E. Modelling and Optimization of Nonlinear Polymerization Processes. In Macromolecular Symposia; Wiley Online Library: Hoboken, NJ, USA, 2016.

28. Zabisky, R.; Chan, W.-M.; Gloor, P.; Hamielec, A. A kinetic model for olefin polymerization in high-pressure tubular reactors: A review and update. Polymer 1992, 33, 2243-2262. [CrossRef]

29. Ray, W.H. On the mathematical modeling of polymerization reactors. J. Macromol. Sci. Rev. Macromol. Chem. Phys. 1972, 8, 1-56. [CrossRef]

30. Kiparissides, C. Polymerization reactor modeling: A review of recent developments and future directions. Chem. Eng. Sci. 1996, 51, 1637-1659. [CrossRef]

31. Tobita, H.; Hamielec, A. Modeling of network formation in free radical polymerization. Macromolecules 1989, 22, 3098-3105. [CrossRef]

32. Tefera, N.; Weickert, G.; Westerterp, K. Modeling of free radical polymerization up to high conversion. I. A method for the selection of models by simultaneous parameter estimation. J. Appl. Polym. Sci. 1997, 63, 1649-1661.

33. Zhou, W.; Marshall, E.; Oshinowo, L. Modeling LDPE tubular and autoclave reactors. Ind. Eng. Chem. Res. 2001, 40, 5533-5542. [CrossRef]

34. Kiparissides, C.; Daskalakis, G.; Achilias, D.; Sidiropoulou, E. Dynamic simulation of industrial poly (vinyl chloride) batch suspension polymerization reactors. Ind. Eng. Chem. Res. 1997, 36, 1253-1267. [CrossRef]

35. Zhu, S.; Hamielec, A. Modeling of free-radical polymerization with crosslinking: monoradical assumption and stationary-state hypothesis. Macromolecules 1993, 26, 3131-3136. [CrossRef]

36. Louie, B.M.; Carratt, G.M.; Soong, D.S. Modeling the free radical solution and bulk polymerization of methyl methacrylate. J. Appl. Polym. Sci. 1985, 30, 3985-4012. [CrossRef] 
37. Tefera, N.; Weickert, G.; Westerterp, K. Modeling of free radical polymerization up to high conversion. II. Development of a mathematical model. J. Appl. Polym. Sci. 1997, 63, 1663-1680. [CrossRef]

38. Brandolin, A.; Lacunza, M.; Ugrin, P.; Capiati, N. High pressure polymerization of ethylene. An improved mathematical model for industrial tubular reactors. Polym. React. Eng. 1996, 4, 193-241.

39. Prasad, V.; Schley, M.; Russo, L.P.; Bequette, B.W. Product property and production rate control of styrene polymerization. J. Process Control 2002, 12, 353-372. [CrossRef]

40. Hutchinson, R.A. Modeling of free-radical polymerization kinetics with crosslinking for methyl methacrylate/ethylene glycol dimethacrylate. Polym. React. Eng. 1993, 1, 521-577. [CrossRef]

41. Barry, J.T.; Berg, D.J.; Tyler, D.R. Radical cage effects: Comparison of solvent bulk viscosity and microviscosity in predicting the recombination efficiencies of radical cage pairs. J. Am. Chem. Soc. 2016, 138, 9389-9392. [CrossRef]

42. Srinivasan, S.; Lee, M.W.; Grady, M.C.; Soroush, M.; Rappe, A.M. Computational study of the self-initiation mechanism in thermal polymerization of methyl acrylate. J. Phys. Chem. A 2009, 113, 10787-10794. [CrossRef]

43. Srinivasan, S.; Lee, M.W.; Grady, M.C.; Soroush, M.; Rappe, A.M. Self-initiation mechanism in spontaneous thermal polymerization of ethyl and n-butyl acrylate: A theoretical study. J. Phys. Chem. A 2010, 114, 7975-7983. [CrossRef] [PubMed]

44. Srinivasan, S.; Rappe, A.M.; Soroush, M. Theoretical Insights Into Thermal Self-Initiation Reactions of Acrylates. In Computational Quantum Chemistry; Elsevier: Amsterdam, The Netherlands, 2019; pp. 99-134.

45. Barner-Kowollik, C.; Beuermann, S.; Buback, M.; Castignolles, P.; Charleux, B.; Coote, M.L.; Hutchinson, R.A.; Junkers, T.; Lacík, I.; Russell, G.T. Critically evaluated rate coefficients in radical polymerization-7. Secondary-radical propagation rate coefficients for methyl acrylate in the bulk. Polym. Chem. 2014, $5,204-212$.

46. Soroush, M.; Rappe, A.M. Theoretical Insights Into Chain Transfer Reactions of Acrylates. In Computational Quantum Chemistry; Elsevier: Amsterdam, The Netherlands, 2019; pp. 135-193.

47. Cuccato, D.; Mavroudakis, E.; Dossi, M.; Moscatelli, D. A Density Functional Theory Study of Secondary Reactions in n-Butyl Acrylate Free Radical Polymerization. Macromol. Theory Simul. 2013, 22, 127-135. [CrossRef]

48. Van Steenberge, P.H.; Vandenbergh, J.; Reyniers, M.-F.; Junkers, T.; D’hooge, D.R.; Marin, G.B. Kinetic Monte Carlo generation of complete electron spray ionization mass spectra for acrylate macromonomer synthesis. Macromolecules 2017, 50, 2625-2636. [CrossRef]

49. Drache, M.; Stehle, M.; Mätzig, J.; Brandl, K.; Jungbluth, M.; Namyslo, J.C.; Schmidt, A.; Beuermann, S. Identification of $\beta$ scission products from free radical polymerizations of butyl acrylate at high temperature. Polym. Chem. 2019, 10, 1956-1967. [CrossRef]

50. Hutchinson, R.A. Modeling of chain length and long-chain branching distributions in free-radical polymerization. Macromol. Theory Simul. 2001, 10, 144-157. [CrossRef]

51. Liu, S.; Srinivasan, S.; Grady, M.C.; Soroush, M.; Rappe, A.M. Backbiting and $\beta$-scission reactions in free-radical polymerization of methyl acrylate. Int. J. Quantum Chem. 2014, 114, 345-360. [CrossRef]

52. Spiegel, M.R. Mathematical Handbook of Formulas and Tables; Schaum's Outline Series; McGraw-Hill: New York, NY, USA, 1968.

53. Brandrup, J.; Immergut, E.H.; Grulke, E.A.; Abe, A.; Bloch, D.R. Polymer Handbook; Wiley: New York, NY, USA, 1999; Volume 89.

54. Moghadam, N.; Liu, S.; Srinivasan, S.; Grady, M.C.; Soroush, M.; Rappe, A.M. Computational study of chain transfer to monomer reactions in high-temperature polymerization of alkyl acrylates. J. Phys. Chem. A 2013, 117, 2605-2618. [CrossRef]

55. Hungenberg, K.-D.; Wulkow, M. Modeling and Simulation in Polymer Reaction Engineering: A Modular Approach; John Wiley \& Sons: Hoboken, NJ, USA, 2018.

56. Arzamendi, G.; Plessis, C.; Leiza, J.R.; Asua, J.M. Effect of the intramolecular chain transfer to polymer on PLP/SEC experiments of alkyl acrylates. Macromol. Theory Simul. 2003, 12, 315-324. [CrossRef]

57. Nikitin, A.N.; Hutchinson, R.A.; Buback, M.; Hesse, P. Determination of intramolecular chain transfer and midchain radical propagation rate coefficients for butyl acrylate by pulsed laser polymerization. Macromolecules 2007, 40, 8631-8641. [CrossRef]

58. Peck, A.N.; Hutchinson, R.A. Secondary reactions in the high-temperature free radical polymerization of butyl acrylate. Macromolecules 2004, 37, 5944-5951. [CrossRef] 
59. Nikitin, A.N.; Hutchinson, R.A.; Wang, W.; Kalfas, G.A.; Richards, J.R.; Bruni, C. Effect of Intramolecular Transfer to Polymer on Stationary Free-Radical Polymerization of Alkyl Acrylates, 5-Consideration of Solution Polymerization up to High Temperatures. Macromol. React. Eng. 2010, 4, 691-706. [CrossRef]

60. Ballard, N.; Hamzehlou, S.; Asua, J.M. Intermolecular transfer to polymer in the radical polymerization of n-butyl acrylate. Macromolecules 2016, 49, 5418-5426. [CrossRef]

61. Hamzehlou, S.; Ballard, N.; Reyes, Y.; Aguirre, A.; Asua, J.; Leiza, J. Analyzing the discrepancies in the activation energies of the backbiting and $\beta$-scission reactions in the radical polymerization of $n$-butyl acrylate. Polym. Chem. 2016, 7, 2069-2077. [CrossRef]

62. Drache, M.; Hosemann, B.; Laba, T.; Beuermann, S. Modeling of Branching Distributions in Butyl Acrylate Polymerization Applying Monte Carlo Methods. Macromol. Theory Simul. 2015, 24, 301-310. [CrossRef]

63. Hamzehlou, S.; Reyes, Y.; Hutchinson, R.; Leiza, J.R. Copolymerization of n-Butyl Acrylate and Styrene: Terminal vs Penultimate Model. Macromol. Chem. Phys. 2014, 215, 1668-1678. [CrossRef]

64. Kockler, K.B.; Haehnel, A.P.; Junkers, T.; Barner-Kowollik, C. Determining Free-Radical Propagation Rate Coefficients with High-Frequency Lasers: Current Status and Future Perspectives. Macromol. Rapid Commun. 2016, 37, 123-134. [CrossRef]

65. Wang, W.; Hutchinson, R.A. High temperature semibatch free radical copolymerization of styrene and butyl acrylate. In Macromolecular Symposia; Wiley Online Library: Hoboken, NJ, USA, 2010.

66. Hlalele, L.; Klumperman, B. In situ 1H NMR studies of high-temperature nitroxide-mediated polymerization of n-butyl acrylate. Macromolecules 2011, 44, 7100-7108. [CrossRef]

67. Barth, J.; Buback, M.; Hesse, P.; Sergeeva, T. Termination and transfer kinetics of butyl acrylate radical polymerization studied via SP-PLP-EPR. Macromolecules 2010, 43, 4023-4031. [CrossRef]

68. Vir, A.B.; Marien, Y.W.; van Steenberge, P.H.; Barner-Kowollik, C.; Reyniers, M.-F.; Marin, G.B.; D’hooge, D.R. From n-butyl acrylate Arrhenius parameters for backbiting and tertiary propagation to $\beta$-scission via stepwise pulsed laser polymerization. Polym. Chem. 2019, 10, 4116-4125. [CrossRef]

69. Buback, M.; Kuelpmann, A.; Kurz, C. Termination kinetics of methyl acrylate and dodecyl acrylate free-radical homopolymerizations up to high pressure. Macromol. Chem. Phys. 2002, 203, 1065-1070. [CrossRef]

70. Shahnazari, M.; Samandari-Masouleh, L.; Emami, S. Equipment capacity optimization of an educational building's CCHP system by genetic algorithm and sensitivity analysis. Energy Equip. Syst. 2017, 5, 375-387. 